An original review paper submitted to the journal of Applied Catalysis B: Environmental

\title{
Glycerol hydrogenolysis into useful C3 chemicals
}

\author{
Daolai Sun, ${ }^{\mathrm{a}}$ Yasuhiro Yamada, ${ }^{\mathrm{a}}$ Satoshi Sato, ${ }^{\mathrm{a} *}$ Wataru Ueda ${ }^{\mathrm{b}}$ \\ ${ }^{a}$ Graduate School of Engineering, Chiba University, Chiba, 263-8522, Japan \\ ${ }^{b}$ Department of Material and Life Chemistry, Faculty of Engineering, Kanagawa University, \\ Kanagawa, 221-8686, Japan. \\ * Corresponding author. Tel. +81 43290 3376; Fax: +81 432903401 \\ E-mail address: satoshi@faculty.chiba-u.jp (S. Sato)
}

\begin{abstract}
Applications of renewable biomass provide facile routes to alleviate the shortage of fossil fuels as well as to reduce the emission of $\mathrm{CO}_{2}$. Glycerol, which is currently produced as a waste in the biodiesel production, is one of the most attractive biomass resources. In the past decade, the conversion of glycerol into useful chemicals has attracted much attention, and glycerol is mainly converted by steam reforming, hydrogenolysis, oxidation, dehydration, esterification, carboxylation, acetalization, and chlorination. In this review, we focused on the catalytic hydrogenolysis of glycerol into C3 chemicals, which contain many industrially important products such as 1,2-propanediol, 1,3-propanediol, allyl alcohol, 1-propanol and propylene. In the hydrogenolysis of glycerol into propanediols, advantages and disadvantages of liquid- and vapor-phase reactions are compared. In addition, recent studies on catalysts, reaction conditions, and proposed pathways are primarily summarized and discussed. Furthermore, new research trends are introduced in connection with the hydrogenolysis of glycerol into allyl alcohol, propanols and propylene.
\end{abstract}

Keywords: glycerol, hydrogenolysis, 1,2-propanediol, 1,3-propanediol, allyl alcohol, 1-propanol, propylene. 


\section{Introduction}

Biomass is biological material derived from living organisms, and it represents abundant carbon-neutral renewable resources for the production of bioenergy and biochemicals, which can replace the energy and the materials produced from fossil resources. In recent years, applications of the biomass resources have attracted much attention from the view point of $\mathrm{CO}_{2}$ emission. Shifting society's dependence away from petroleum to renewable biomass resources is essential for the development of sustainable industrial societies and efficient management of greenhouse gas emissions [1]. The bio-derived chemicals are mainly produced by two types of main components of sugars: hexoses and pentose, which can be obtained from starch, cellulose and hemicellulose [2]. Bioenergy usually means biofuels, which mainly consist of bioethanol and biodiesel, and the production of those fuels has been increasing rapidly in the last decade [3]. The bioethanol production depends heavily on the fermentation of starch obtained from corn and sugar cane [4].

Glycerol is the smallest polyol available from triglycerides, vegetable oil and animal fat, which constitute approximately $10 \mathrm{wt} . \%$ of total biomass [5]. Biodiesel is produced from triglycerides by transesterification with short chain alcohols through catalysis by alkali, and a huge amount of glycerol, $c a .10 \mathrm{wt} . \%$ of the overall biodiesel production, is generated as the by-product in the process [6]. Consequently, glycerol constitutes $c a$. $1 \mathrm{wt} . \%$ of total biomass. The production of biodiesel is 22.7 million metric tons in 2012, and it increases rapidly and is even forecasted to increase to 36.9 million metric tons in 2020 [7]. Glycerol is also produced as a by-product of ethanol production by fermentation of sugars. Although the extraction of glycerol from this residue is not economically feasible, the fermentation of sugar into ethanol is also a potential additional resource of glycerol [8]. In the cleavage processes of fatty acids, the purity of the crude glycerol is high and ca. $80 \mathrm{wt} . \%$ glycerol aqueous solution can be obtained from most of the conventional processes of biodiesel production, but it also contains water, methanol, traces of fatty acids as well as various inorganic and organic impurities [9,10]. Crude glycerol has to be purified by distillation prior to further use in most cases, whereas the cost of the distillation is high. Furthermore, although glycerol has been produced at a large quantity with a rapid growth, the market of glycerol is small and the price of glycerol is low [9]. As a consequence, the proportion of refined glycerol is actually steadily 
decreasing and the unrefined crude glycerol is generally disposed by burning, which must be considered as a waste of a potentially useful organic raw material [10]. Thus, new economical ways of using glycerol must be developed in order to substantially increase the demand and the price of crude glycerol, and also to ensure the sustainability of the biodiesel production. Glycerol can be a starting material for further chemical derivatization, and many useful intermediates and specialty chemicals can be produced by catalytic reactions [11-13].

The catalytic conversion of glycerol into useful chemicals are mainly performed through stream reforming, oxidation, dehydration, acetalization, esterification, etherification, carboxylation, and chlorination, which have been summarized in many review papers at different periods [2,11,14-17]. Among the various ways for glycerol derivatization, the dehydration of glycerol into acrolein, the oxidation of glycerol into dihydroxyacetone and glyceric acid, and the hydrogenolysis of glycerol into 1,2-propanediol (1,2-PDO) and 1,3-propanediol (1,3-PDO) have been intensively investigated because of the wide and important use of the corresponding chemicals (Scheme 1). Dehydration of glycerol into acrolein has been well summarized in some review papers [7,10,18-21]. Although high acrolein selectivity has been obtained over some solid acid catalysts in many reports, the catalysts are deactivated rapidly in most cases and the development of solid catalysts for a stable acrolein formation from glycerol is still required. Because acrolein is mainly used for acrylic acid formation, the direct production of acrylic acid from glycerol is also attractive. In recent 5 years, direct synthesis of acrylic acid from glycerol has been extensively reported [22-37]. In the processes, acrolein is generated as an intermediate and it is further oxidized into acrylic acid under either $\mathrm{O}_{2}$ or air flow conditions.

The oxidation of glycerol into dihydroxyacetone and glyceric acid has been reviewed $[38,39]$. Supported precious metals, such as $\mathrm{Pt}, \mathrm{Pd}$ and $\mathrm{Au}$, are generally used as catalysts for glycerol oxidation into both dihydroxyacetone and glyceric acid. The features of the supported precious metals, such as the particle size and the acid-base conditions, significantly affect the selectivity to the oxidized products. In the latest review paper [39], a detailed summary has been reported on the glycerol oxidation into glyceric acid over Au-based catalysts, which show more advantages than the traditional Pt- and Pd-based catalysts. Lactic acid is another attractive chemical 
which can be derived via oxidation [40-55]. The catalyst system for glycerol oxidation into lactic acid is similar to that into glyceric acid, whereas the reaction conditions are much different: the formation of lactic acid requires much higher reaction temperatures and a basic media is indispensable in most cases. The glycerol oxidation is expected to be applied for further studies and even industrial applications.

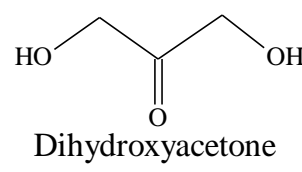<smiles>CCCCCCCC(C)O</smiles>

Glyceric acid

\section{Glycerol}

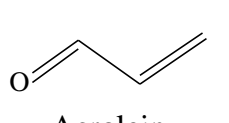

Acrolein

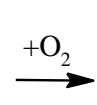<smiles>CCCCC</smiles>

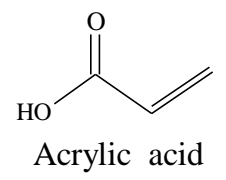

Acrylic acid

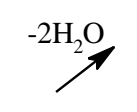

\section{西}


discussed. Although new achievements are summarized in review papers for the recent 5 years [56-65], the advantages and disadvantages of vapor- and liquid-phase reactions are less discussed. In addition, some important achievements have been reported in the past 5 years. In addition, allyl alcohol is an attractive target chemical, which is also an intermediate in glycerol hydrogenolysis, but it is difficult to be produced selectively because it is easy to be further hydrogenated into 1-propanol under $\mathrm{H}_{2}$ flow conditions. Consequently, efforts have been made to produce allyl alcohol from glycerol by hydrogen-transfer reactions using either monoalcohols or formic acid as the H-donor molecule. Recently, glycerol multi-step hydrogenolysis into propanols and propylene has also attracted much attention. In this review, the new trends in the glycerol hydrogenolysis are also summarized and discussed.

\section{1,2-Propanediol}

1,2-PDO is a valuable chemical used widely in the synthesis of pharmaceuticals, polymers, agricultural adjuvants, plastics, and transportation fuel [66-68]. Depending on its purity, 1,2-PDO can be used as an antifreeze agent, a hydraulic fluid, and a solvent, and it has also usages for cosmetics and food applications [69]. 1,2-PDO is currently produced by the hydration of propylene oxide, which is produced through the selective oxidation of propylene [62]. Because propylene is produced from fossil resources, the production of 1,2-PDO from bio-derived glycerol is attractive. Glycerol hydrogenolysis into 1,2-PDO is extensively investigated in a liquid-phase reaction under high $\mathrm{H}_{2}$ pressure conditions, and several studies focused on vapor-phase reactions has also been reported. Many kinds of transition metals, such as $\mathrm{Pt}, \mathrm{Pd}, \mathrm{Ru}, \mathrm{Ir}, \mathrm{Cu}$, and $\mathrm{Ni}$, are effective for 1,2-PDO formation. In the following sections, we divide and summarize the previous studies by the catalyst systems as well as by the reaction conditions.

\subsection{Reaction route of glycerol hydrogenolysis into 1,2-propanediol}

The reported formation route of glycerol hydrogenolysis into 1,2-PDO is different according to the catalyst system and the reaction phase. Generally, a catalyst system with both dehydration and hydrogenation ability is required for the reaction. In the liquid-phase reactions, it is 
generally accepted that acid sites catalyze the dehydration of glycerol into acetol, which is further hydrogenated into 1,2-PDO over transition metal catalysts, such as $\mathrm{Pt}, \mathrm{Ru}$, and $\mathrm{Cu}$ (Scheme 2) [5,6,70-71]. Alhanash et al. performed the glycerol dehydration over Zn-Cr mixed oxide catalysts at a $\mathrm{Zn} / \mathrm{Cr}$ ratio of $1: 1$, which gives $40 \%$ selectivity to acetol at $18 \%$ conversion, and proposed a reaction mechanism of glycerol dehydration into acetol over Lewis acid sites, as shown in Scheme 3, in which $\mathrm{M}$ represents the Lewis acid sites [72]. It is proposed that the terminal $\mathrm{OH}$ group of glycerol rather than the internal one is more likely to interact with a Lewis acid site. Concerted the transfer of the terminal $\mathrm{OH}$ group to the Lewis acid site and the migration of the $\mathrm{H}^{+}$from the internal carbon atom to the bridging $\mathrm{O}$ atom of the oxide gave 2,3-dihydroxypropene, which is further tautomerized to yield acetol. In contrast, Brønsted acid sites are also proposed to catalyze glycerol dehydration into acetol, as shown in Scheme 4 [5], in which acetol is formed via direct dehydration of glycerol and the subsequent keto-enol tautomerization. Scheme 2 also shows a generally accepted formation route of 1,2-PDO under alkaline conditions. Dehydrogenation of glycerol firstly proceeds over metal sites assisted by the base to form glyceraldehyde, which dehydrates to 2-hydroxy-2-propenal over base sites, and finally 1,2-PDO is produced from 2-hydroxy-2-propenal via two-step hydrogenation process $[5,6]$. Tomishige's group has performed a series of works on liquid-phase glycerol hydrogenolysis into 1,2-PDO and 1,3-PDO over Ir and Ru catalysts modified with $\mathrm{ReO}_{\mathrm{x}}$ [6], and proposed a direct glycerol hydrogenolysis route with different coordination (Fig. 1). It is suggested that glycerol is firstly adsorbed on the surface of $\mathrm{ReO}_{\mathrm{x}}$ clusters to form alkoxide species of 2,3-dihydroxypropoxide. Then, the hydride attacking the 2-position of the hydroxyl group of 2,3-dihydroxypropoxide gives 1,3-PDO, while the hydride attacking the 3-position of the hydroxyl group of 2,3-dihydroxyisopropoxide gives 1,2-PDO [73]. 


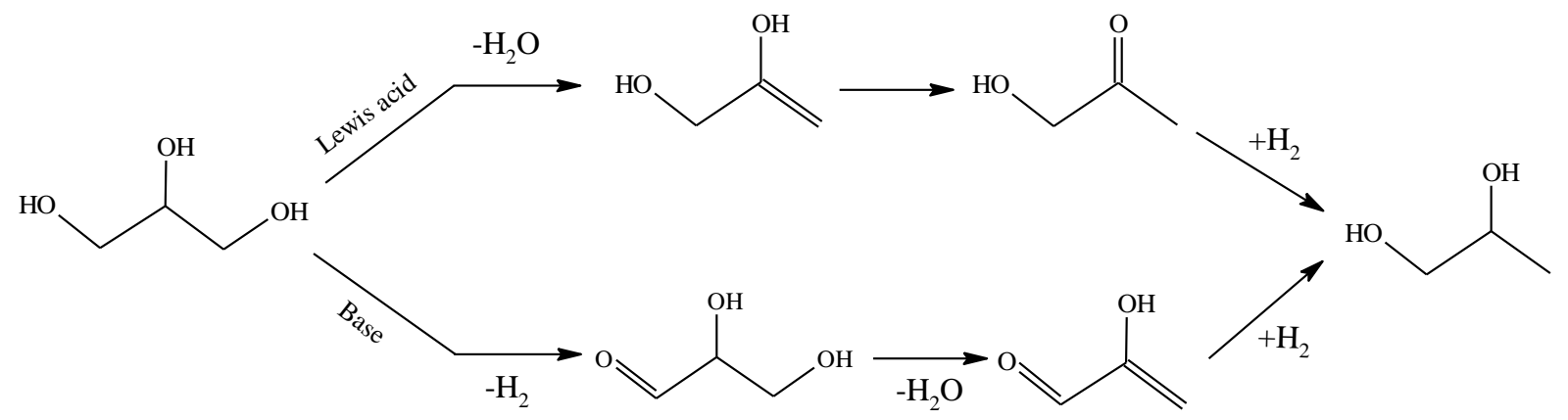

Scheme 2 Reaction routes of glycerol hydrogenolysis into 1,2-PDO [5].
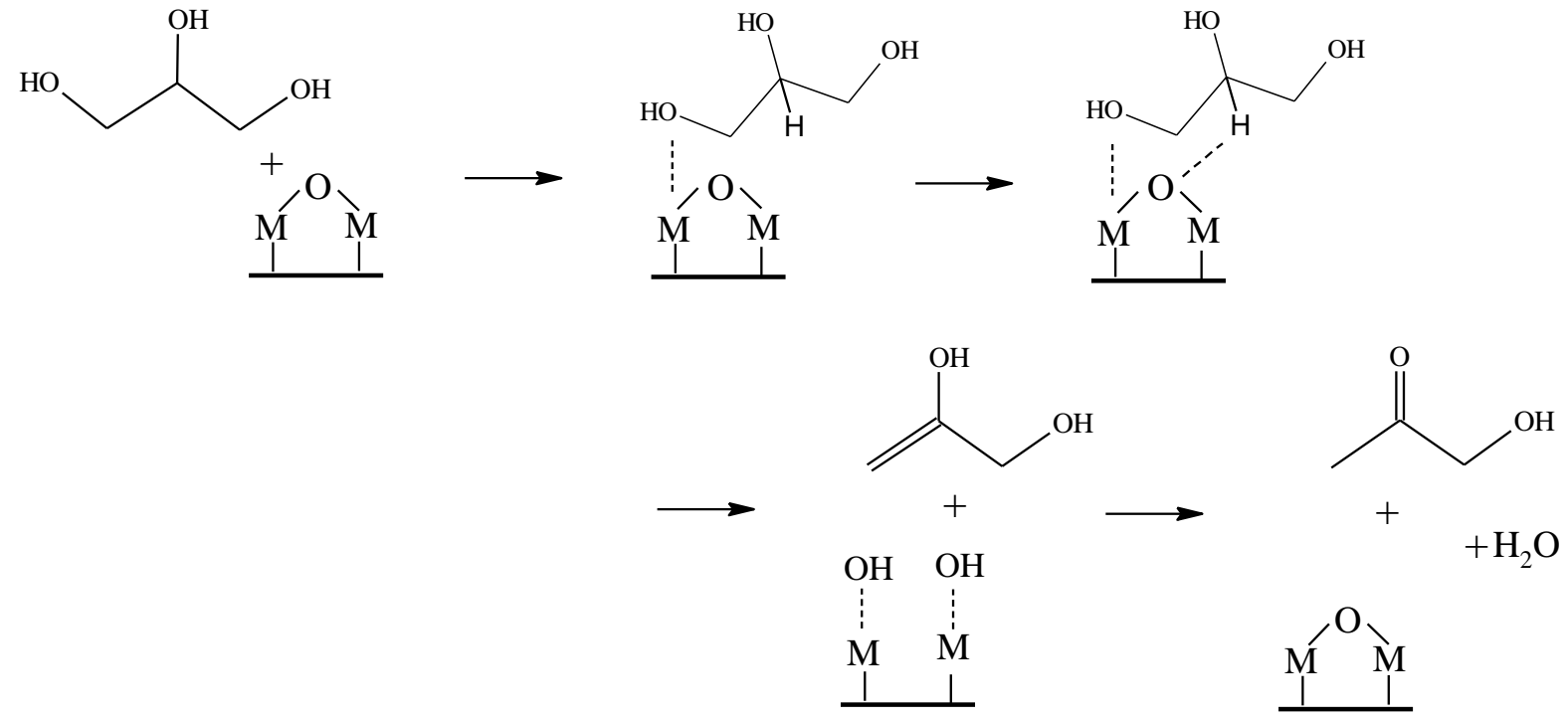

Scheme 3 Reaction mechanism of glycerol dehydration into acetol over Lewis acid sites proposed by Alhanash et al. [72].

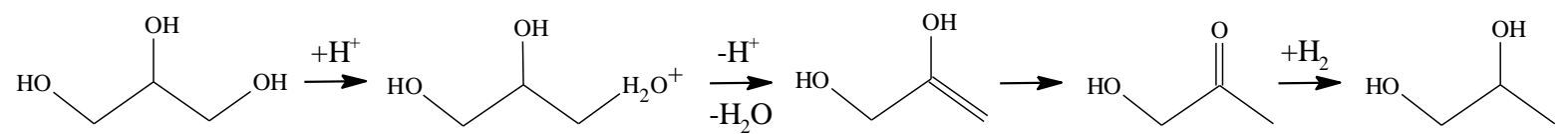

Scheme 4 Reaction mechanism of glycerol dehydration into acetol over Brønsted acid sites [5, 62]. 
(a)

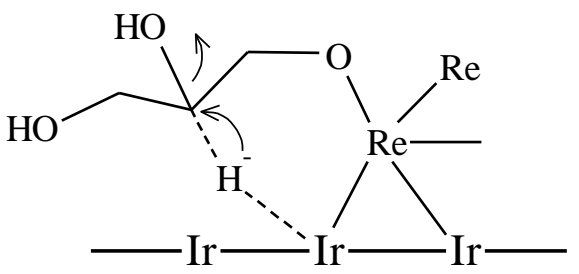

(b)

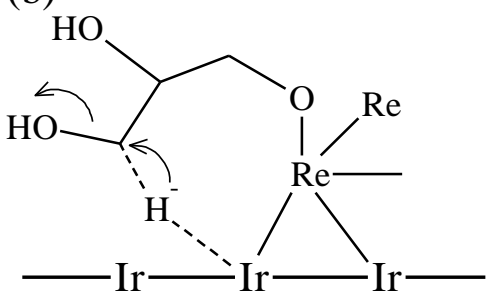

Figure 1 Direct glycerol hydrogenolysis mechanism proposed by Tomishige et al. [73].

(a) Glycerol hydrogenolysis to 1,3-PDO; (b) Glycerol hydrogenolysis to 1,2-PDO

Sato's group has continued a series of works on vapor-phase glycerol hydrogenolysis into 1,2-PDO [74-77]. $\mathrm{Al}_{2} \mathrm{O}_{3}$ - and $\mathrm{Cr}_{2} \mathrm{O}_{3}$-supported $\mathrm{Cu}$ catalysts show high activity for the formation of 1,2-PDO from glycerol, and it is confirmed that acetol is generated as the intermediate. In order to determine the active sites for acetol formation from glycerol, vapor-phase reactions of glycerol is performed under $\mathrm{N}_{2}$ atmosphere [78]: $\mathrm{Cu}$ supported on $\mathrm{Al}_{2} \mathrm{O}_{3}$ gives $82.9 \%$ selectivity to acetol at a complete conversion, whereas $\mathrm{Al}_{2} \mathrm{O}_{3}$ gives $26.5 \%$ selectivity to acetol at $11.5 \%$ conversion at $250{ }^{\circ} \mathrm{C}$. Furthermore, $84.6 \%$ acetol selectivity can be achieved at $74.9 \%$ glycerol conversion over Raney $\mathrm{Cu}$ without acid sites. Schmidt et al. have also reported that higher than 94\% 1,2-PDO yield is obtained from glycerol over Raney $\mathrm{Cu}$ under $\mathrm{H}_{2}$ flow conditions [79,80]. These results indicate that $\mathrm{Cu}$ metal provides the active sites for the dehydration of glycerol into acetol, and the supports such as $\mathrm{Al}_{2} \mathrm{O}_{3}$ work as a mere support not as an acid catalyst. In other words, $\mathrm{Cu}$ metal catalyzes the glycerol dehydration into acetol as well as the following hydrogenation of acetol into 1,2-PDO. For 1,2-PDO used as a reactant, on the other hand, $\mathrm{Cu}$ metal catalyzes the dehydrogenation of 1,2-PDO to acetol but never acts as a dehydration catalyst to produce propanal and allyl alcohol. That is why Cu metal selectively works as a catalyst for the selective formation of 1,2-PDO from glycerol. It is probable that $\mathrm{Cu}$ metal surface provides the active sites for the catalytic glycerol hydrogenolysis in a vapor phase. A radical mechanism in the glycerol dehydration catalyzed by $\mathrm{Cu}$ metal is proposed in Scheme 5 [78]. There are two possible reaction routes, the elimination of one hydrogen atom from a primary and secondary $\mathrm{OH}$ group of glycerol initiates the dehydration. In both routes, a hydroxy radical is eliminated after the elimination of the hydrogen atom. In addition, supported Ag catalysts 
are tested for glycerol dehydration under $\mathrm{N}_{2}$ atmosphere, and $\mathrm{SiO}_{2}$-supported $\mathrm{Ag}$ metal catalyst gives the acetol selectivity of $91.1 \%$ with $46.1 \%$ glycerol conversion at $240{ }^{\circ} \mathrm{C}$ [76]. Furthermore, an $\mathrm{Ag}$ powder can give $84.6 \%$ selectivity to acetol at $30.8 \%$ conversion even in $\mathrm{H}_{2}$ atmosphere. Therefore, it is proved that transition metals, such as $\mathrm{Cu}$ and $\mathrm{Ag}$, can provide active sites for the dehydration of glycerol into acetol.

(a)<smiles>OCC(O)CO</smiles>

$\mathrm{Cu} \mathrm{Cu} \mathrm{Cu}$<smiles>CC(CO)O[C](Cl)Cl</smiles><smiles>C=C(O)CO</smiles><smiles>CC(=O)CO</smiles>

$\mathrm{Cu} \mathrm{Cu} \mathrm{Cu}$

(b)<smiles>OCC(O)CO</smiles>

$\mathrm{H} \cdot$<smiles>[GeH3][GeH3]</smiles><smiles>C[C@H](O)CO[C@H](C)[C@H](O)Cl</smiles><smiles>C=C(O)CO</smiles>

$\mathrm{Cu} \mathrm{Cu} \mathrm{Cu}$

$\mathrm{Cu} \mathrm{Cu} \mathrm{Cu}$

Scheme 5 Reaction mechanism of glycerol dehydration into acetol over $\mathrm{Cu}$ metal proposed by Sato et al. [78].

In liquid-phase reactions, although the glycerol dehydration step is generally accepted to be catalyzed by either an acid or a base (Scheme 2), we have different opinions. We are afraid that the transition metals, such as $\mathrm{Pt}, \mathrm{Ru}$, and $\mathrm{Cu}$, do not only work as a hydrogenation catalyst, but also involve the glycerol dehydration into acetol, which is further hydrogenated into 1,2-PDO. Based on the abundant reports performed in liquid phase [81-115], we found that the species of the loaded metals significantly affect the selectivity to 1,2-PDO rather than the acid-base properties of the supports. For example, higher than 90\% 1,2-PDO selectivity can be obtained over $\mathrm{Cu}$ catalyst supported on chromite [90], $\mathrm{ZrO}_{2}$ [91], $\mathrm{ZnO}$ [92], boehmite [93], $\mathrm{Al}_{2} \mathrm{O}_{3}$ [94], $\mathrm{SiO}_{2}$ [95], $\mathrm{MgO}$ [96] and $\mathrm{MgAlO}$ [97]. These metal oxides seem to work only as inert supports for dispersing $\mathrm{Cu}$ but do not seem to catalyze the first-step dehydration of glycerol into acetol in the formation of 1,2-PDO. 
Indeed, in the vapor-phase glycerol dehydration, acetol is difficult to be selectively obtained over metal oxides catalysts, such as $\mathrm{Al}_{2} \mathrm{O}_{3}$ [78], $\mathrm{ZrO}_{2}$, and $\mathrm{TiO}_{2}$ [105]. In the liquid-phase glycerol hydrogenolysis into 1,2-PDO, an acidic support catalyzed selective dehydration of glycerol into acetol also has been never proved by experiments. On the contrary, $\mathrm{Cu} / \mathrm{Al}_{2} \mathrm{O}_{3}$ shows high activity for 1,2-PDO formation, while $\mathrm{Al}_{2} \mathrm{O}_{3}$ gives $0 \%$ selectivity to acetol at a low conversion of $7 \%$ under the same reaction conditions [94]. Hirunsit et al. [94] performed DFT calculations, which demonstrate that the $\mathrm{Al}_{2} \mathrm{O}_{3}$ support facilitates $\mathrm{Cu}$ to be more active toward interacting with glycerol and acetol intermediate species. Mane et al. firstly reported a detailed study focusing on the mechanism of liquid-phase glycerol dehydration into acetol over Cu-supported catalysts [106]. Ba-, Mg-, Zr-, Zn-, $\mathrm{Al}-$, and $\mathrm{Cr}-$ modified $\mathrm{Cu}$ catalysts were studied to understand the role of active species in selective glycerol dehydration to acetol. $\mathrm{Cu}-\mathrm{Al}, \mathrm{Cu}-\mathrm{Zr}$, and $\mathrm{Cu}-\mathrm{Mg}$ showed relatively high activity and gave acetol selectivities of 92,87 , and $79 \%$ at conversions of 24,21 and $24 \%$, respectively, at $220{ }^{\circ} \mathrm{C}$ under an $\mathrm{N}_{2}$ ambient pressure. In contrast, metallic $\mathrm{Cu}$ and acidic catalysts such as $\mathrm{Al}_{2} \mathrm{O}_{3}$ and $\mathrm{ZrO}_{2}$ showed extremely low activity with low glycerol conversions less than $2 \%$. They concluded that glycerol dehydration to acetol is not only catalyzed by acid sites but also by the metallic $\mathrm{Cu}$. Raney catalysts were also investigated for the liquid-phase glycerol hydrogenolysis to 1,2-PDO [90,99,116]. Montassier et al. firstly reported that Raney $\mathrm{Cu}$ gave $86 \%$ selectivity to 1,2-PDO with a conversion higher than $80 \%$ at $240{ }^{\circ} \mathrm{C}$ and an $\mathrm{H}_{2}$ pressure of 30 atm [116]. Raney $\mathrm{Ni}$ is reported to give $77 \%$ 1,2-PDO selectivity with $63 \%$ conversion at $190{ }^{\circ} \mathrm{C}$ and an $\mathrm{H}_{2}$ pressure of 10 atm [99], and Raney $\mathrm{Cu}$ is also reported to give $69 \%$ 1,2-PDO selectivity with $49 \%$ conversion at $200{ }^{\circ} \mathrm{C}$ and an $\mathrm{H}_{2}$ pressure of $14 \mathrm{~atm}$ [90], respectively. These results indicate that transition metals, such as $\mathrm{Cu}$ and $\mathrm{Ni}$, can also effectively catalyze the first-step dehydration of glycerol to acetol even in a liquid phase.

Comparing to the reaction mechanisms initiated by an acid or a base (Scheme 2-4), we suppose that metal-oxide concerted mechanism (Fig. 1) is acceptable in a liquid-phase reaction. On the other hand, it is also possible that the supported metal singly provides the active sites to catalyze the liquid-phase dehydration of glycerol into acetol at temperatures as high as those at which the dehydrogenation could proceed. 


\subsection{Liquid-phase glycerol hydrogenolysis into 1,2-PDO over precious metal catalysts}

Table 1 summarizes some representative reports of glycerol hydrogenolysis to 1,2-PDO in liquid phase over supported precious metal catalysts [81-88]. Feng et al. have investigated glycerol hydrogenolysis over basic oxide-supported $\mathrm{Ru}$ catalysts, such as $\mathrm{Ru} / \mathrm{CeO}_{2}, \mathrm{Ru} / \mathrm{La}_{2} \mathrm{O}_{3}$, and $\mathrm{Ru} / \mathrm{MgO}$ [84]. Among the tested catalysts, $\mathrm{Ru} / \mathrm{CeO}_{2}$ has the smallest $\mathrm{Ru}$ particle size and the weakest surface basicity feature, and it is effective to promote 1,2-PDO formation from glycerol: $62.7 \%$ selectivity to 1,2-PDO at $85.2 \%$ conversion is obtained over $\mathrm{Ru} / \mathrm{CeO}_{2}$ at $180{ }^{\circ} \mathrm{C}$ and an $\mathrm{H}_{2}$ pressure of $50 \mathrm{~atm}$, and the by-products contain propanols, which are generated via 1,2-PDO further hydrogenolysis, and glycerol decomposition products such as methanol, ethanol, and ethylene glycol. Lee et al. prepared a series of Ru-supported hydrotalcite-like and $\mathrm{Ca}-\mathrm{Zn}$-modified hydrotalcite-like catalysts for 1,2-PDO formation from glycerol [87]. They indicated that the support with strong acidity is effective for $\mathrm{Ru}$ dispersion and highly dispersed $\mathrm{Ru}$ can promote both the conversion and the 1,2-PDO selectivity. Hamzah et al. also reported that small Ru particles are effective for 1,2-PDO formation [86]. They have found that a mixed support of bentonite and $\mathrm{TiO}_{2}$ at a weight ratio of 1:2 improves the dispersion of Ru and the catalytic activity. An 80.6\% 1,2-PDO selectivity is achieved at a low temperature of $150{ }^{\circ} \mathrm{C}$ and an $\mathrm{H}_{2}$ pressure of $20 \mathrm{~atm}$, and ethylene glycerol is generated as the main by-product with a selectivity of $c a$. 10\%. Gandarias et al. studied glycerol hydrogenolysis over $\mathrm{SiO}_{2}-\mathrm{Al}_{2} \mathrm{O}_{3}$-supported $\mathrm{Pt}$ catalyst, and they indicate that the acid sites of $\mathrm{SiO}_{2}-\mathrm{Al}_{2} \mathrm{O}_{3}$ are responsible for glycerol dehydration to acetol while Pt metal sites catalyze the acetol hydrogenation to 1,2-PDO [81]. Pt also catalyzes C-C bond cleavage reactions, whereas it inhibits the formation of coke. The maximum selectivity to 1,2-PDO is $31.9 \%$ : further hydrogenolysis products, such as 1-propanol and 2-propanol, are produced with high total selectivity.

Furikado et al. have studied glycerol hydrogenolysis over supported precious metal, such as $\mathrm{Rh}, \mathrm{Ru}, \mathrm{Pt}$, and $\mathrm{Pd}[82] . \mathrm{Rh} / \mathrm{SiO}_{2}$ exhibits a high activity to form glycerol hydrogenolysis products such as propanediols and propanols, while the maximum selectivity to 1,2-PDO was $34.6 \%$ because of the further hydrogenation of 1,2-PDO into 1-propanol. The catalytic activity is further promoted by the loading of $\mathrm{Re}$ onto $\mathrm{Rh} / \mathrm{SiO}_{2}$, whereas the selectivity to 1,2-PDO is maximized at $46.9 \%$ because of competitive formation of 1,3-PDO and propanols [83]. Auneau et al. studied supported Ir 
catalysts for glycerol transformation in the presence of $\mathrm{NaOH}$ in an $\mathrm{H}_{2}$ atmosphere [85]. Ir/C gives a $76 \%$ selectivity to $1,2-\mathrm{PDO}$ with $85.0 \%$ conversion at $180{ }^{\circ} \mathrm{C}$ and an $\mathrm{H}_{2}$ pressure of $50 \mathrm{~atm}$. Zhou et al. reported that $\mathrm{Al}_{2} \mathrm{O}_{3}$-supported $\mathrm{Ag}$ catalyst affords high 1,2-PDO selectivity of $96.0 \%$ with $46 \%$ conversion at $220{ }^{\circ} \mathrm{C}$ and $15 \mathrm{~atm}$ [88]. Although high 1,2-PDO selectivity is achieved, the catalytic activity of $\mathrm{Ag} / \mathrm{Al}_{2} \mathrm{O}_{3}$ is not so high because of the low hydrogenation ability of $\mathrm{Ag}$.

In the above-mentioned studies, we know that almost all the precious metals can be used for glycerol hydrogenation into 1,2-PDO, while the supports play an important role on the catalytic activity of the precious metals. The studies similarly indicate that the acid-base property of the support affects the dispersion of the precious metals, and highly dispersed precious metal catalysts show high catalytic activity for 1,2-PDO formation from glycerol. Although the liquid-phase reactions are performed at relatively low temperatures, the $\mathrm{C}-\mathrm{C}$ bond cleavage products of glycerol, such as methanol, ethanol, and ethylene glycol, are still by-produced at a certain amount over the precious metal catalysts, except Ag [81-87]. In some reports [81-83], it is described that a high yield of 1,2-PDO is difficult to be achieved because 1,2-PDO further converts into propanols. However, this could be a common problem in the liquid-phase glycerol hydrogenolysis, especially when an acidic metal oxide is used as the support because it catalyzes the further dehydration of 1,2-PDO into propanal [89]. As shown in Table 1, both the high conversion and the high selectivity are difficult to be achieved at the same time, which indicates that 1,2-PDO is usually unstable in liquid-phase catalytic conditions and that consecutive reactions occur. In another word, a long reaction time is usually required for achieving high conversions of glycerol in a liquid phase, whereas the resulting 1,2-PDO is easier to be further converted into propanols and even propylene for a long reaction time. 
Table 1 Liquid-phase 1,2-propanediol formation from glycerol over precious metal catalysts.

\begin{tabular}{cccccccc}
\hline Catalyst & Temp. & $\mathrm{H}_{2}$ & Glycerol/ & Time & Conversion & Selectivity to & Ref. \\
& & pressure & Catalyst & & of glycerol & $1,2-\mathrm{PDO}$ & \\
& $\left({ }^{\circ} \mathrm{C}\right)$ & $(\mathrm{atm})$ & $(\mathrm{g} / \mathrm{g})$ & $(\mathrm{h})$ & $(\%)$ & $(\%)$ & \\
\hline $\mathrm{Pt} / \mathrm{SiO}_{2}-\mathrm{Al}_{2} \mathrm{O}_{3}$ & 220 & 45 & 6.0 & 24 & 19.8 & 31.9 & 81 \\
$\mathrm{Rh} / \mathrm{SiO}_{2}$ & 120 & 80 & 27.8 & 10 & 19.6 & 34.6 & 82 \\
$\mathrm{Rh} / \mathrm{Re}^{-\mathrm{SiO}_{2}}$ & 120 & 80 & 27.8 & 2 & 38.4 & 46.9 & 83 \\
$\mathrm{Ru} / \mathrm{CeO}_{2}$ & 180 & 50 & 12.5 & 10 & 85.2 & 62.7 & 84 \\
$\mathrm{Ir} / \mathrm{C}$ & 180 & 50 & 10.1 & 24 & 85.0 & 76.0 & 85 \\
$\mathrm{Ru} / \mathrm{bentonite}-\mathrm{TiO} \mathrm{O}_{2}$ & 150 & 20 & 4.8 & 7 & 69.8 & 80.6 & 86 \\
$\mathrm{Ru} / \mathrm{CaZnMgAlO}$ & 180 & 25 & 34.8 & 18 & 58.5 & 85.5 & 87 \\
$\mathrm{Ag} / \mathrm{Al}_{2} \mathrm{O}_{3}$ & 220 & 15 & 7.6 & 10 & 46.0 & 96.0 & 88 \\
\hline
\end{tabular}

\subsection{Liquid-phase glycerol hydrogenolysis into 1,2-PDO over base metal catalysts}

Table 2 summarizes base metals such as $\mathrm{Cu}, \mathrm{Ni}$, and $\mathrm{Co}$ which have been also extensively studied for liquid-phase hydrogenolysis of glycerol into 1,2-PDO [89-99]. In an early report, Suppes et al. studied glycerol hydrogenolysis using various commercial catalysts, and copper-chromite was found to show a high activity for 1,2-PDO formation [90]: an 89.6\% 1,2-PDO selectivity with $65.3 \%$ conversion was obtained. Balaraju et al. prepared a series of $\mathrm{Cu} / \mathrm{ZnO}$ catalysts with different $\mathrm{Cu} / \mathrm{Zn}$ ratios for glycerol hydrogenolysis [92]. $\mathrm{Cu} / \mathrm{ZnO}$ catalyst with a $\mathrm{Cu} / \mathrm{Zn}$ weight ratio of 50/50 shows a 1,2-PDO selectivity of $92 \%$ at $37 \%$ conversion. The 1,2-PDO selectivity is maximized at $92 \%$ because it decreases with increasing the conversion at a longer reaction time. Based on the physicochemical properties of $\mathrm{Cu} / \mathrm{ZnO}$ catalysts measured by XRD and the reaction results, they indicated that the sufficient amount of $\mathrm{ZnO}$ and $\mathrm{Cu}$ with small particle size is required for glycerol conversion and achieving high 1,2-PDO selectivity. Vasiliadou et al. prepared various $\mathrm{SiO}_{2}$-supported $\mathrm{Cu}$ catalysts with large crystals, small monodispersed crystallites and a highly dispersed XRD amorphous $\mathrm{Cu}$ phase [95]. Their results show that different dispersion characteristics result in different conversion of glycerol at a range of $20-50 \%$, while all the catalysts give high 
selectivity to $1,2-\mathrm{PDO}$ at a range of $92-97 \%$. Wu et al. have prepared highly dispersed $\mathrm{Cu}$ clusters $(<1 \mathrm{~nm})$ over boehmite via an aqueous chemical reduction method and compared the catalytic activity with that of $\mathrm{Cu} / \mathrm{Al}_{2} \mathrm{O}_{3}, \mathrm{Cu} / \mathrm{SiO}_{2}$ and $\mathrm{Ru} / \mathrm{C}$ [93]. $\mathrm{Cu} /$ boehmite shows the highest activity for 1,2-PDO formation among the tested catalysts, which is illustrated to assign to the small particle size of $\mathrm{Cu}$ and the Lewis acid sites of boehmite. A complete conversion of glycerol was achieved at a reaction time of $12 \mathrm{~h}$, whereas the selectivity to $1,2-\mathrm{PDO}$ decreases to $\mathrm{ca} .85 \%$ and the selectivity to propanols increases to $c a$. $13 \%$.

Basic metal oxides-supported $\mathrm{Cu}$ is also effective for 1,2-PDO formation from glycerol. In a report of Yuan's group, a 97.6\% 1,2-PDO selectivity with a glycerol conversion of $72 \%$ was achieved over $\mathrm{Cu} / \mathrm{MgO}$ [96]. The activity of the $\mathrm{Cu} / \mathrm{MgO}$ depends strongly on the particle sizes of both $\mathrm{Cu}$ and $\mathrm{MgO}$ : the catalysts with smaller sized $\mathrm{Cu}$ and $\mathrm{MgO}$ particles are more active. The same group also prepared a $\mathrm{Cu} / \mathrm{MgAlO}$ catalyst, which is synthesized via thermal decomposition of the as-synthesized $\mathrm{Cu}_{0.4} \mathrm{Mg}_{5.6} \mathrm{Al}_{2}(\mathrm{OH})_{16} \mathrm{CO}_{3}$ with layered double hydroxides. Comparing with the catalysts prepared by an impregnation and an ion-exchange method, $\mathrm{Cu}$ prepared by thermal decomposition is highly dispersed on $\mathrm{MgAlO}$ support and 98.2\% 1,2-PDO selectivity with $80.0 \%$ conversion is obtained at $180{ }^{\circ} \mathrm{C}$ and an $\mathrm{H}_{2}$ pressure of 30 atm [97]. Furthermore, the 1,2-PDO selectivity only slightly decreases to $c a .97 \%$ when the conversion increases to $c a$. $95 \%$. 
Table 2 Liquid-phase 1,2-propanediol formation from glycerol over base metal catalysts.

\begin{tabular}{cccccccc}
\hline Catalyst & Temp. & $\mathrm{H}_{2}$ & Glycerol/ & Time & Conversion & Selectivity to & Ref. \\
& & pressure & Catalyst & & of glycerol & 1,2 -PDO & \\
& $\left({ }^{\circ} \mathrm{C}\right)$ & $(\mathrm{atm})$ & $(\mathrm{g} / \mathrm{g})$ & $(\mathrm{h})$ & $(\%)$ & $(\%)$ & \\
\hline Copper-chromite & 200 & 21 & Unclear & 24 & 65.3 & 89.6 & 90 \\
$\mathrm{Cu} / \mathrm{ZrO}_{2}$ & 200 & 40 & 16.7 & 8 & 10.0 & 90.0 & 91 \\
$\mathrm{Cu} / \mathrm{ZnO}$ & 200 & 20 & 17.4 & 16 & 37 & 92 & 92 \\
$\mathrm{Cu} / \mathrm{boehmite}$ & 200 & 40 & 20 & 6 & 77.5 & 92.5 & 93 \\
$\mathrm{Cu} / \mathrm{Al} \mathrm{O}_{3}$ & 220 & 50 & 10 & 6 & 61 & 93.3 & 94 \\
$\mathrm{Cu} / \mathrm{SiO} \mathrm{O}_{2}$ & 240 & 80 & 166.7 & 5 & 51.9 & 96.6 & 95 \\
$\mathrm{Cu} / \mathrm{MgO}$ & 180 & 30 & 7.1 & 20 & 72.0 & 97.6 & 96 \\
$\mathrm{Cu} / \mathrm{MgAlO}$ & 180 & 30 & 7.1 & 20 & 80 & 98.2 & 97 \\
$\mathrm{Co} / \mathrm{ZnAlO}$ & 200 & 20 & 13.3 & 12 & 70.6 & 57.8 & 98 \\
$\mathrm{Raney} \mathrm{Ni}$ & 190 & 10 & 4 & 20 & 63 & 77 & 99 \\
\hline
\end{tabular}

$\mathrm{Co}$ and $\mathrm{Ni}$ also show catalytic activity for 1,2-PDO formation from glycerol, whereas the selectivity to 1,2-PDO is lower than that of $\mathrm{Cu}$ because $\mathrm{Co}$ and $\mathrm{Ni}$ promote the $\mathrm{C}-\mathrm{C}$ cleavage and increase ethylene glycol and/or ethanol selectivity [98,99]. In the glycerol hydrogenolysis over $\mathrm{Co} / \mathrm{ZnAlO}$ catalyst prepared by a co-precipitation method followed by reduction at $600{ }^{\circ} \mathrm{C}$ [98], the selectivity to $1,2-\mathrm{PDO}$ is maximized at $57.8 \%$ at $200{ }^{\circ} \mathrm{C}$, and the selectivities to ethylene glycol and ethanol are 21.0 and $4.5 \%$, respectively. Perosa et al. studied the glycerol hydrogenolysis over Raney-Ni catalyst: the selectivities to 1,2-PDO and ethanol are 77 and 15\%, respectively, even at a low temperature of $190{ }^{\circ} \mathrm{C}$ and an $\mathrm{H}_{2}$ pressure of $10 \mathrm{~atm}$ [99].

Among the three base metals, $\mathrm{Cu}$ shows the highest activity for 1,2-PDO formation. Because of the competitive formation of glycerol C-C cleavage products, such as methanol, ethanol and ethylene glycol, 1,2-PDO cannot be selectively produced over $\mathrm{Co}$ - and Ni-based catalysts $[98,99]$. The 1,2-PDO selectivities higher than $90 \%$ can be achieved over most of the $\mathrm{Cu}$-supported catalysts [90-97], and $\mathrm{Cu}$ with small particle sizes is preferable for 1,2-PDO formation [91-93, 
95-97]. Comparing with precious metals, $\mathrm{Cu}$ has low $\mathrm{C}-\mathrm{C}$ cleavage ability and higher 1,2-PDO selectivity. The selectivity to $\mathrm{C}-\mathrm{C}$ bond-cleavage products over $\mathrm{Cu}$-based catalysts is at most $3 \%$ [90-97]. However, in most of the liquid-phase reactions using acidic supports, 1,2-PDO selectivity decreases at high conversion levels because further hydrogenolysis of 1,2-PDO proceeds for a long reaction time. On the other hand, high 1,2-PDO selectivity can be maintained at high conversion levels over $\mathrm{Cu}$ supported on basic supports [96,97], although hydrogenolysis of 1,2-PDO still proceeds slowly with increasing the reaction time.

\subsection{Liquid-phase glycerol hydrogenolysis into 1,2-PDO over bimetallic catalysts}

Bimetallic catalysts are prepared in some studies to promote the catalytic activity toward 1,2-PDO formation from glycerol, as shown in Table 3 [100-104]. Li et al. prepared supported Pd-Re bimetallic catalysts by an impregnation method for glycerol hydrogenolysis [100]. They indicate that the added Re might have an interaction with Pd and can increase the ability of the catalysts for the activation of a C-O bond. The proposed reaction mechanism is shown in Fig 2. The addition of Re also increases the acidity of the Pd-Re catalysts, whereas it decreases the selectivity to 1,2-PDO due to the further hydrogenolysis of 1,2-PDO into lower alcohols under acidic conditions. However, basic oxides-supported Pd-Re catalysts can promote the conversion of glycerol, and also maintain the selectivity to 1,2-PDO. $89.3 \%$ selectivity to $1,2-\mathrm{PDO}$ at $52.9 \%$ conversion is achieved over $\mathrm{Pd}-\mathrm{Re} / \mathrm{La}_{2} \mathrm{O}_{3}$.

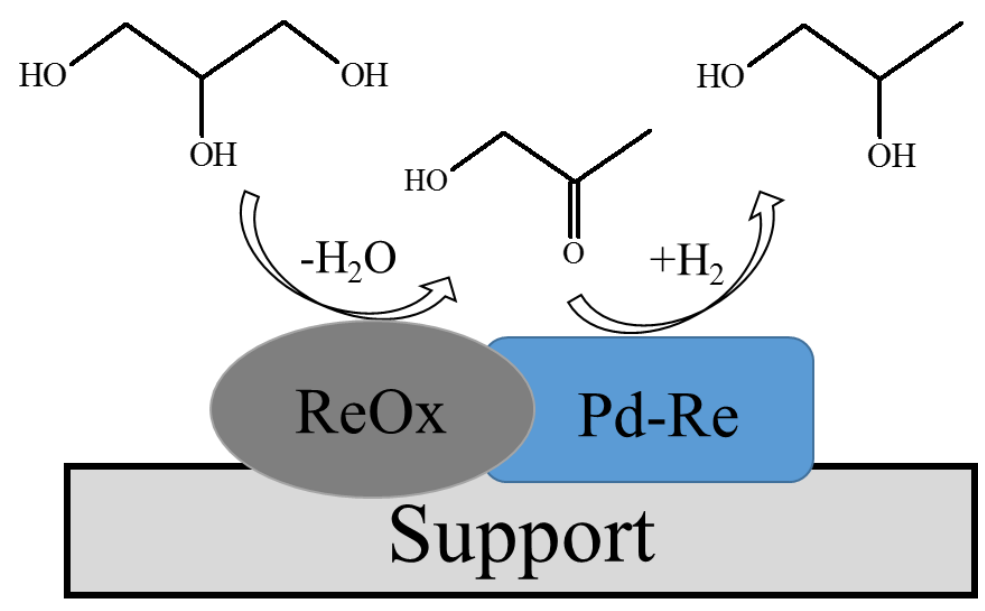

Figure 2 Proposed mechanism of glycerol hydrogenolysis over supported Pd-Re bimetallic catalysts [100]. 
Because $\mathrm{Cu}$ shows low $\mathrm{C}-\mathrm{C}$ cleavage ability and gives high 1,2-PDO selectivity as described in Section 2.3, Cu in bimetallic catalysts of precious metals, such as $\mathrm{Ru}$ and $\mathrm{Pd}$, with $\mathrm{Cu}$ improve the catalytic activity. Salazar et al. have studied $\mathrm{TiO}_{2}$ supported $\mathrm{Cu}-\mathrm{Ru}$ bimetallic catalysts for glycerol hydrogenolysis into 1,2-PDO: the addition of $\mathrm{Cu}$ metal to a Ru-based catalyst significantly enhances the selectivity toward 1,2-PDO and the appropriate mass ratio of $\mathrm{Cu} / \mathrm{Ru}$ is $1: 1$ [101]. The selectivity to $1,2-\mathrm{PDO}$ is $90 \%$ at $39 \%$ conversion over $\mathrm{Cu}-\mathrm{Ru} / \mathrm{TiO}_{2}$ whereas the 1,2-PDO selectivity is only $57 \%$ at $31 \%$ conversion over $\mathrm{Ru} / \mathrm{TiO}_{2}$ at the same reaction conditions. The role of $\mathrm{Cu}$ is illustrated to disperse large $\mathrm{Ru}$ agglomerates which are responsible for $\mathrm{C}-\mathrm{C}$ bond cleavage to form ethylene glycol. Bentonite-supported $\mathrm{Cu}$-Ru bimetallic catalysts are also effective for 1,2-PDO formation from glycerol, and the selectivity to 1,2-PDO and ethylene glycol is 86.4 and $9.4 \%$, respectively, at $100 \%$ conversion at $230{ }^{\circ} \mathrm{C}$ and an $\mathrm{H}_{2}$ pressure of $100 \mathrm{~atm}$ at a $\mathrm{Ru} / \mathrm{Cu}$ molar ratio of 3:1 [102].

Zhou et al. have prepared a series of $\mathrm{Ag}$-modified $\mathrm{Cu} / \mathrm{Al}_{2} \mathrm{O}_{3}$ catalysts and studied the effect of $\mathrm{Ag}$ loading on the catalytic activity [103]. The reactions are performed at $200{ }^{\circ} \mathrm{C}$ and an $\mathrm{H}_{2}$ pressure of 15 atm over $\mathrm{Cu}-\mathrm{Ag} / \mathrm{Al}_{2} \mathrm{O}_{3}$ without pre-reduction, and a $96 \%$ selectivity to $1,2-\mathrm{PDO}$ is achieved at $27 \%$ conversion over $\mathrm{Cu}-\mathrm{Ag} / \mathrm{Al}_{2} \mathrm{O}_{3}$ with a $\mathrm{Cu} / \mathrm{Ag}$ molar ratio of 7:3. Based on the characterization results of TPR and XPS, it is indicated that the formation of low valence Cu species $\left(\mathrm{Cu}^{0}\right.$ or $\left.\mathrm{Cu}^{+}\right)$is the key for high activity and the addition of $\mathrm{Ag}$ promotes the reduction of the $\mathrm{Cu}$ species, which results in the generation of low valence $\mathrm{Cu}$ species. The addition of $\mathrm{Ag}$ is also illustrated to improve the dispersion of the $\mathrm{Cu}$ species, which increases the catalytic activity. $\mathrm{Pd}_{0.04} \mathrm{Cu}_{0.4} / \mathrm{Mg}_{5.56} \mathrm{Al}_{2} \mathrm{O}_{8.56}(\mathrm{Cu}-\mathrm{Pd} / \mathrm{MgAlO})$ catalysts were prepared via thermal decomposition of $\mathrm{Pd}_{\mathrm{x}} \mathrm{Cu}_{0.4} \mathrm{Mg}_{5.6-\mathrm{x}} \mathrm{Al}_{2}(\mathrm{OH})_{16} \mathrm{CO}_{3}$ precursors with layered double hydroxides for glycerol hydrogenolysis by Xia et al. [104]. Cu-Pd/MgAlO with highly dispersed $\mathrm{Pd}$ and $\mathrm{Cu}$ shows higher catalytic activity than mono-metallic Pd- and Cu-supported catalysts. A high 1,2-PDO selectivity of $97.2 \%$ with a glycerol conversion of $76.9 \%$ is achieved over $\mathrm{Cu}-\mathrm{Pd} / \mathrm{MgAlO}$ at $180{ }^{\circ} \mathrm{C}$ and an $\mathrm{H}_{2}$ pressure of $20 \mathrm{~atm}$. They concluded that the high catalytic performance of $\mathrm{Cu}-\mathrm{Pd} / \mathrm{MgAlO}$ is attributed to the $\mathrm{H}_{2}$ spillover from $\mathrm{Pd}$ to $\mathrm{Cu}$ as shown in Fig 3. Although the results of the reaction of $\mathrm{Cu}-\mathrm{Pd} / \mathrm{MgAlO}$ is similar with that of the $\mathrm{Cu} / \mathrm{MgAlO}$ catalyst [97], which has been is reported by the 
same group [104], the reaction using bimetallic catalyst is performed at a lower $\mathrm{H}_{2}$ pressure condition with shorter reaction time.

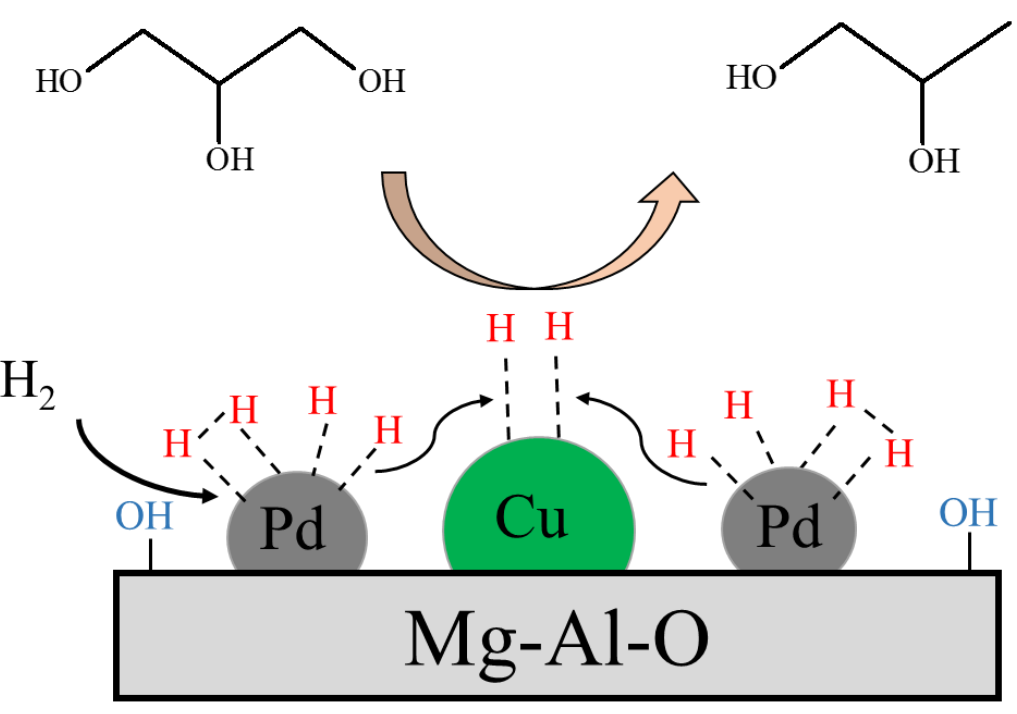

Figure 3 Proposed mechanism of glycerol hydrogenolysis over $\mathrm{Cu}-\mathrm{Pd} / \mathrm{MgAlO}$ catalyst [104].

We summarize the catalytic activity of various catalysts mentioned in Sections 2.2-2.4 in Fig. 4. The conversion-selectivity plots in the hydrogenolysis indicate that $\mathrm{Cu}$ and $\mathrm{Cu}$-containing bimetallic catalysts are efficient and selective to form 1,2-PDO from glycerol in a liquid phase.

Table 3 Liquid-phase 1,2-propanediol formation from glycerol over bimetallic metal catalysts.

\begin{tabular}{|c|c|c|c|c|c|c|c|}
\hline Catalyst & $\begin{array}{l}\text { Temp. } \\
\left({ }^{\circ} \mathrm{C}\right)\end{array}$ & $\mathrm{H}_{2}$ pressure & $\begin{array}{l}\text { Glycerol/ } \\
\text { Catalyst } \\
\text { (g/g) }\end{array}$ & $\begin{array}{l}\text { Time } \\
\text { (h) }\end{array}$ & $\begin{array}{l}\text { Conversion } \\
\text { of glycerol } \\
(\%)\end{array}$ & $\begin{array}{c}\text { Selectivity to } \\
\text { 1,2-PDO } \\
(\%)\end{array}$ & Ref. \\
\hline $\mathrm{Pd}-\mathrm{Re} / \mathrm{La}_{2} \mathrm{O}_{3}$ & 200 & 80 & 29.1 & 18 & 52.9 & 89.3 & 100 \\
\hline $\mathrm{Cu}-\mathrm{Ru} / \mathrm{TiO}_{2}$ & 200 & 25 & 46.2 & 12 & 39 & 90 & 101 \\
\hline $\mathrm{Cu}-\mathrm{Ru} /$ bentonite & 230 & 100 & 5.5 & 18 & 100 & 86.4 & 102 \\
\hline $\mathrm{Cu}-\mathrm{Ag} / \mathrm{Al}_{2} \mathrm{O}_{3}$ & 200 & 15 & Unclear & 10 & 27 & 96.0 & 103 \\
\hline $\mathrm{Cu}-\mathrm{Pd} / \mathrm{MgAlO}$ & 180 & 20 & 7.1 & 10 & 76.9 & 97.2 & 104 \\
\hline
\end{tabular}




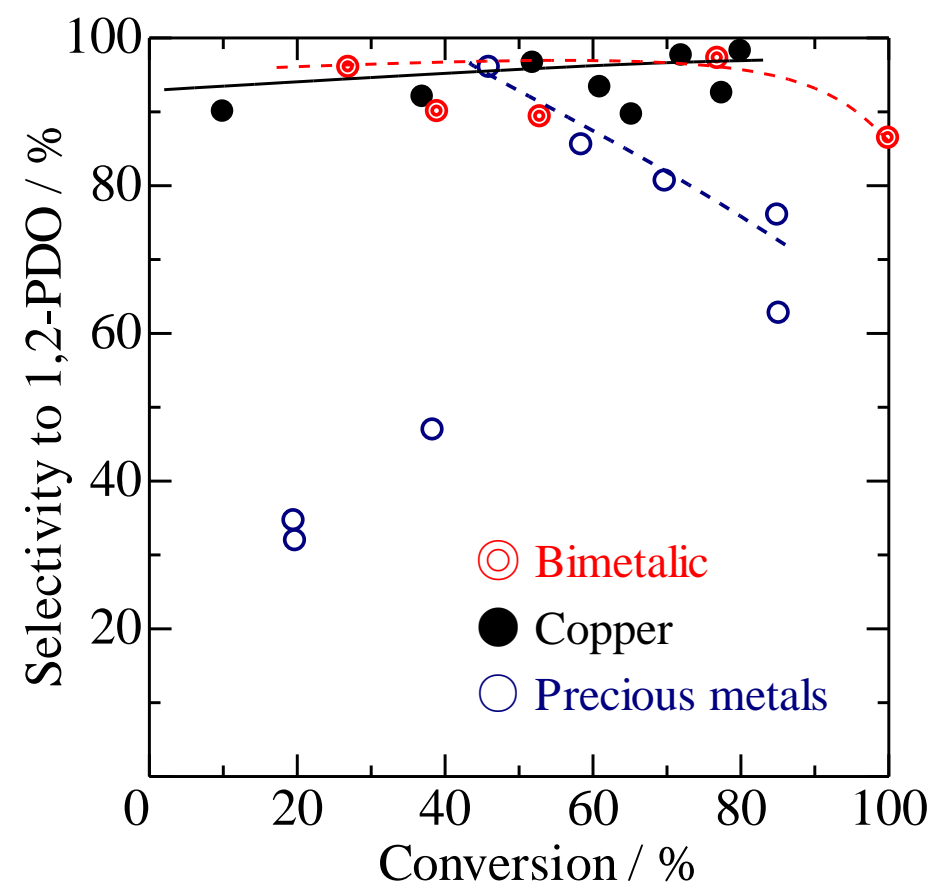

Figure 4 Conversion-selectivity plots in the glycerol hydrogenolysis in liquid phase.

Open, closed, and double circles represent the data listed in Tables 2, 3, and 4, respectively, while the data for $\mathrm{Co} / \mathrm{ZnO} / \mathrm{AlO}$ and Raney Ni catalysts in Table 3 are not addressed.

\subsection{Liquid-phase glycerol hydrogenolysis into 1,2-PDO using hydrogen generated in situ}

External supply of hydrogen is necessary for all the above-mentioned hydrogenolysis processes for producing 1,2-PDO from glycerol. The use of hydrogen gas as an $\mathrm{H}$ donor is common in a hydrogenolysis process, whereas a high $\mathrm{H}_{2}$ pressure is always necessary and a pressure tight reaction equipment is required, which increases the production cost. One interesting alternative is to produce 1,2-PDO from glycerol hydrogenolysis using the hydrogen generated in situ from H-containing molecules via hydrogen transfer. Martin et al. have summarized glycerol hydrogenolysis into propanediols using hydrogen generated in situ [60]. The in situ-generated hydrogen can be supplied by glycerol itself via aqueous phase reforming as well as by the additive H-containing molecules, such as monoalcohols and formic acid, via catalytic transfer hydrogenation. A hydrogen molecule is produced together with $\mathrm{CO}_{2}$ in the aqueous phase reforming of glycerol, 
while hydrogen atoms transfer from the $\mathrm{H}$ donor to glycerol in a catalytic transfer hydrogenation reaction [60].

Table 4 summarizes new significant reports of glycerol hydrogenolysis into 1,2-PDO using hydrogen generated in situ [107-115]. D’Hondt et al. firstly reported glycerol hydrogenolysis into 1,2-PDO using $\mathrm{H}_{2}$ produced via in-situ reforming of glycerol [107]. NaY zeolite-supported $\mathrm{Pt}$ catalyst gives $64 \%$ selectivity to $1,2-\mathrm{PDO}$ with a glycerol conversion of $85.4 \%$ at $230{ }^{\circ} \mathrm{C}$ under atmospheric conditions. The proposed reaction pathways are shown in Scheme 6. The reforming of glycerol over Pt generates $\mathrm{H}_{2}$ and $\mathrm{CO}_{2}$. The formed $\mathrm{CO}_{2}$ works as an acid, which is proposed to catalyze glycerol dehydration into acetol and the formed $\mathrm{H}_{2}$ is consumed for the later hydrogenation of acetol into 1,2-PDO over Pt. Maria et al. studied glycerol hydrogenolysis over $\mathrm{SiO}_{2}$-supported Pt-Sn catalysts under pressured $\mathrm{N}_{2}$ atmosphere [108]. The suitable amount of additive Sn into $\mathrm{Pt} / \mathrm{SiO}_{2}$ is 0.2 wt.\%, and the maximum 1,2-PDO selectivity is $59 \%$ at $54 \%$ conversion at $200{ }^{\circ} \mathrm{C}$. In the studies $[107,108]$, because a part of glycerol is used for reforming to produce $\mathrm{H}_{2}$, the selectivity to $1,2-\mathrm{PDO}$ is low.

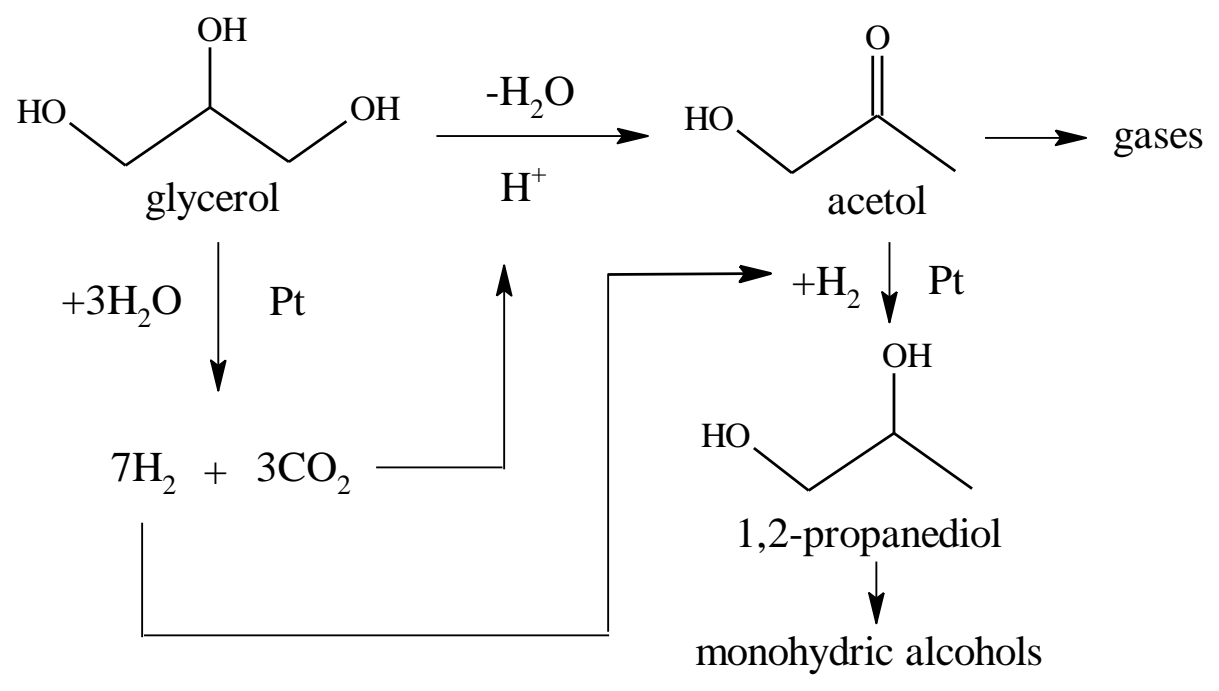

Scheme 6 Reaction routes of glycerol hydrogenolysis into 1,2-PDO in the absence of $\mathrm{H}_{2}$ proposed by D'Hondt et al. [107]. 
Musolino et al. firstly reported glycerol hydrogenolysis via catalytic transfer hydrogenation, in which they used 2-propanol as the H-donor molecule [109]: $\mathrm{PdO} / \mathrm{Fe}_{2} \mathrm{O}_{3}$ is used as the catalyst and $\mathrm{PdO}$ is reduced to $\mathrm{Pd}$ by hydrogen generated from 2-propanol. $94 \%$ selectivity to 1,2-PDO with a complete conversion is achieved at $180{ }^{\circ} \mathrm{C}$ under $5 \mathrm{~atm}$ inert gas atmosphere, and acetone is described to be the only product formed by the oxidation of 2-propanol. Under such a reaction condition, gas products such as $\mathrm{CO}_{2}$ are reasonable to be formed via glycerol reforming over $\mathrm{Pd}$ metal, and propylene is also possible to be formed via 1,2-PDO further hydrogenolysis. However, there is no description about the carbon balance and the analysis of the gas products in the paper. Xia et al. performed glycerol hydrogenolysis over $\mathrm{Cu} / \mathrm{MgAlO}$ catalyst in the presence of an $\mathrm{H}$-donor molecule, such as methanol, ethanol and 2-proapnol, under pressured $\mathrm{N}_{2}$ conditions [110]. Among the tested $\mathrm{H}$ donors, ethanol is proved to be the best hydrogen source. The proposed mechanism is shown in Fig. 5. The dehydrogenation of ethanol yields acetaldehyde, which further converts to ethyl acetate, 1-butanol and 1,1-diethoxyethane. Considering no dihydrogen molecule was detected in the gas phase, it is supposed that hydrogen dehydrogenated from ethanol exists mainly in the form of active hydrogen atom which adsorbed on the surface of the $\mathrm{Cu}$, and then it reacts with acetol quickly. The $\mathrm{Cu} / \mathrm{MgAlO}$ catalyst with a $\mathrm{Cu}: \mathrm{Mg}: \mathrm{Al}: \mathrm{O}$ molar ratio of 0.4:5.6:2:9 shows the largest amount of basic sites and the highest $\mathrm{Cu}$ dispersion degree, and also gives the highest 1,2-PDO selectivity of $93.1 \%$ at a conversion of $93.9 \%$ at $200{ }^{\circ} \mathrm{C}$ and an $\mathrm{N}_{2}$ pressure of $30 \mathrm{~atm}$. Gandarias et al. have conducted a series of works dealing with hydrogen-free glycerol hydrogenolysis over $\mathrm{Ni}-\mathrm{Cu} / \mathrm{Al}_{2} \mathrm{O}_{3}$ in the presence of formic acid, which is used as the H-donor molecule [111-113]. Large loading of Ni promotes acetol hydrogenation into 1,2-PDO, whereas it also increases the selectivities to glycerol decomposition products. A 1,2-PDO selectivity of $81.6 \%$ at $89.9 \%$ conversion is obtained over $\mathrm{Ni}-\mathrm{Cu} / \mathrm{Al}_{2} \mathrm{O}_{3}$ with a Ni/Cu weight ratio of $20: 15$ at $220{ }^{\circ} \mathrm{C}$ and $45 \mathrm{~atm} \mathrm{~N}_{2}$. In a recent study, Mauriello et al. reported a $64 \%$ selectivity to 1,2-PDO with a complete conversion of glycerol over $\mathrm{Pd} / \mathrm{Co}_{3} \mathrm{O}_{4}$ at $180{ }^{\circ} \mathrm{C}$ and $5 \mathrm{~atm} \mathrm{~N}_{2}$ using 2-propanol as the $\mathrm{H}$ donor [114]. The preparation method of the catalysts significantly affects the activity, and the catalysts prepared by a co-precipitated method show the highest catalytic performance toward 1,2-PDO formation. They conclude that the co-precipitation method ensures a strong interaction between Pd and the support, and leads to the 
formation of bimetallic ensembles which positively promote the glycerol catalytic transfer hydrogenolysis reaction. Considering that unreacted methanol remains in the crude glycerol solution in biodiesel production process, Vasiliadou et al. studied hydrogen-free glycerol hydrogenolysis using methanol as the $\mathrm{H}$ donor [115]. The reactions are performed over Pt- or Cu-based catalysts using 7.2 wt.\% methanol and $11.4 \%$ glycerol mixed aqueous solution as the reactant. $\mathrm{Cu} / \mathrm{ZnAlO}$ catalyst prepared by the co-precipitation method shows a relatively high activity and gives a $51.9 \%$ selectivity to 1,2-PDO with a glycerol conversion of $86.6 \%$. In the experiments using labeled ${ }^{13} \mathrm{CH}_{3} \mathrm{OH}$, it is concluded that methanol reformation with water mainly contributes to hydrogen production, and $c a .70 \%$ of the total hydrogen is produced from the reformation of methanol, while the extent of glycerol aqueous phase reforming is limited in the presence of methanol.

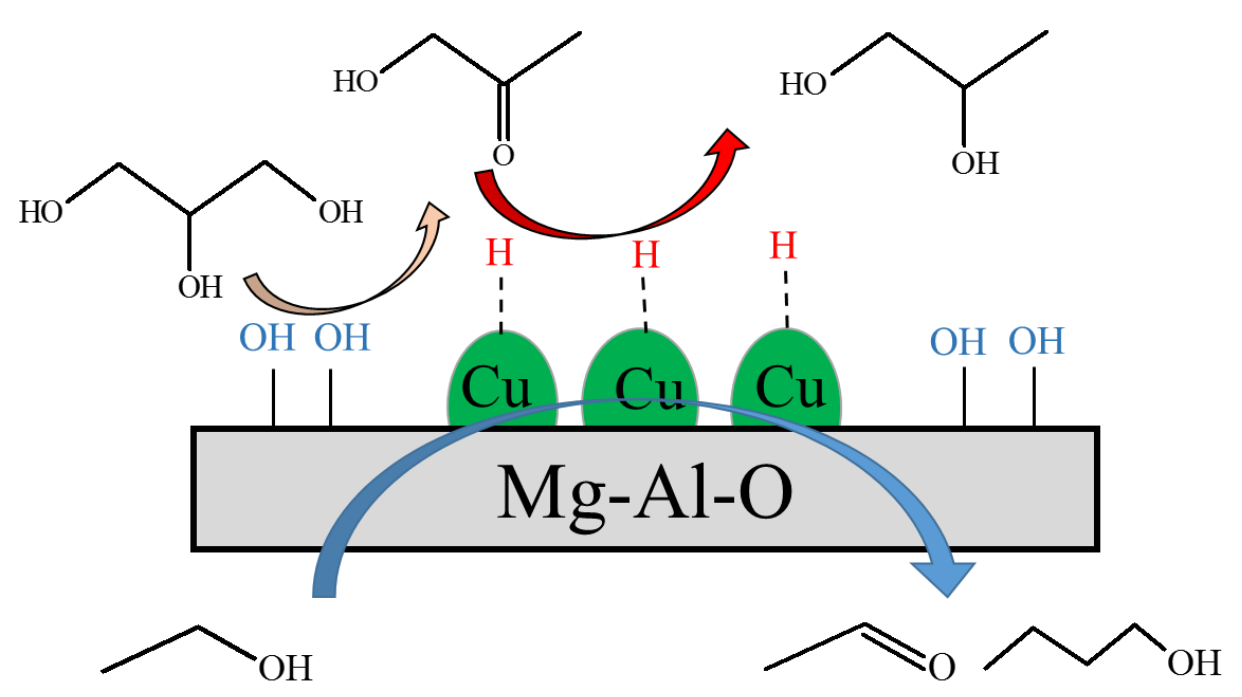

Figure 5 Proposed mechanism of glycerol hydrogenolysis over $\mathrm{Cu} / \mathrm{MgAlO}$ catalyst using ethanol as the H donor [110]. 
Table 4 Liquid-phase 1,2-propanediol formation from glycerol using in-situ generated hydrogen.

\begin{tabular}{|c|c|c|c|c|c|c|c|c|}
\hline Catalyst & $\begin{array}{l}\text { Temp. } \\
\left({ }^{\circ} \mathrm{C}\right)\end{array}$ & $\begin{array}{l}\text { Pressure } \\
\text { (atm) }\end{array}$ & $\begin{array}{l}\text { Solvent } \\
\text { (H donor) }\end{array}$ & $\begin{array}{l}\text { Glycerol/ } \\
\text { Catalyst } \\
\text { (g/g) }\end{array}$ & $\begin{array}{l}\text { Time } \\
\text { (h) }\end{array}$ & $\begin{array}{c}\text { Conversion } \\
\text { of glycerol } \\
(\%)\end{array}$ & $\begin{array}{c}\text { Selectivity to } \\
\text { 1,2-PDO } \\
(\%)\end{array}$ & Ref. \\
\hline $\mathrm{Pt} / \mathrm{NaY}$ zeolite & 230 & 1 (air) & Glycerol & 5.3 & 15 & 85.4 & 64 & 107 \\
\hline $\mathrm{Pt}-\mathrm{Sn} / \mathrm{SiO}_{2}$ & 200 & $4\left(\mathrm{~N}_{2}\right)$ & Glycerol & 4.1 & 2 & 54 & 59 & 108 \\
\hline $\mathrm{Pd} / \mathrm{Fe}_{2} \mathrm{O}_{3}$ & 180 & 5 (inert gas) & 2-propanol & 5.1 & 24 & 100 & 94 & 109 \\
\hline $\mathrm{Cu} / \mathrm{MgAlO}$ & 200 & $30\left(\mathrm{~N}_{2}\right)$ & Ethanol & 8.1 & 10 & 93.9 & 93.1 & 110 \\
\hline $\mathrm{Ni}-\mathrm{Cu} / \mathrm{Al}_{2} \mathrm{O}_{3}$ & 220 & $45\left(\mathrm{~N}_{2}\right)$ & formic acid & 10.9 & 24 & 89.9 & 81.6 & 111 \\
\hline $\mathrm{Pd} / \mathrm{Co}_{3} \mathrm{O}_{4}$ & 180 & $5\left(\mathrm{~N}_{2}\right)$ & 2-propanol & 6.1 & 24 & 100 & 64 & 114 \\
\hline $\mathrm{Cu} / \mathrm{ZnAlO}$ & 220 & $35\left(\mathrm{~N}_{2}\right)$ & Methanol & 1.7 & 4 & 86.6 & 51.9 & 115 \\
\hline
\end{tabular}

Glycerol hydrogenolysis into 1,2-PDO using hydrogen generated in situ have some advantages such as the use of renewable $\mathrm{H}$-donor resources of methanol, ethanol, and formic acid, while the most attractive advantage is that the hydrogen generated in situ can be performed at low or even ambient pressure. On the other hand, the use of additional substances will results in additional by-products and requires the additional separating processes. From this view point, catalytic transfer hydrogenation using $\mathrm{H}$-donor molecules is more preferable than using glycerol aqueous phase reforming because the later generally produces more kinds of by-products. Among the well-used H-donor molecules, such as formic acid, methanol, ethanol, and 2-propanol, formic acid can be considered to be the most preferable one because only $\mathrm{CO}_{2}$ is generated after dehydrogenation and $\mathrm{CO}_{2}$ is easily separated from the liquid products.

\subsection{Vapor-phase glycerol hydrogenolysis into 1,2-PDO}

Vapor-phase glycerol hydrogenolysis into 1,2-PDO is preferable for industrial applications, whereas there are not so many studies dealing with vapor-phase reactions. Table 5 summarizes glycerol hydrogenolysis to 1,2-PDO in vapor phase. Suppes et al. firstly reported vapor-phase hydrogenolysis of glycerol to 1,2-PDO using copper-chromite catalyst [117]. They perform the 
reaction under atmospheric $\mathrm{H}_{2}$ pressure: $55.5 \%$ selectivity to 1,2-PDO and $44.5 \%$ selectivity to acetol at complete glycerol conversion are obtained at $200{ }^{\circ} \mathrm{C}$ at a glycerol aqueous concentration of 2.5 wt.\%. In their further report [118], the effects of reaction conditions are investigated: lower temperatures and higher hydrogen pressures shift the equilibrium from acetol to 1,2-PDO. Lower reaction temperatures also inhibit the formation of glycerol cracking products such as ethylene glycol, and higher than $90 \%$ 1,2-PDO selectivity is achieved at $230{ }^{\circ} \mathrm{C}$ under $\mathrm{H}_{2}$ pressures at a range of 5-15 atm.

Since the dehydration of glycerol needs relatively high reaction temperatures and the hydrogenation of acetol into 1,2-PDO favors low temperatures, Sato et al. developed an efficient direct process which is performed over $\mathrm{Cu} / \mathrm{Al}_{2} \mathrm{O}_{3}$ catalyst at an atmospheric $\mathrm{H}_{2}$ pressure and gradient temperatures: the dehydration of glycerol into acetol is catalyzed by the upper-layer catalyst at high temperature, and the following hydrogenation of acetol into 1,2-PDO is catalyzed by the lower-layer catalyst at low temperature [74,75]. In the system, glycerol can dehydrate to acetol completely and acetol can hydrogenate into 1,2-PDO efficiently: a 96.1\% yield of 1,2-PDO is achieved at a gradient temperature from 200 to $130{ }^{\circ} \mathrm{C}$ under ambient $\mathrm{H}_{2}$ pressure. However, even higher 1,2-PDO yield cannot be achieved because the by-production of ethylene glycol, which is generated by glycerol decomposition over $\mathrm{Cu}$ metal. In our further study, $\mathrm{Ag}$-modified $\mathrm{Cu} / \mathrm{Al}_{2} \mathrm{O}_{3}$ is prepared and found to be effective for reducing the cracking ability of $\mathrm{Cu}$ and inhibiting ethylene glycol formation [77]. Although the formation of ethylene glycol can be inhibited by the loading of $\mathrm{Ag}$ onto $\mathrm{Cu} / \mathrm{Al}_{2} \mathrm{O}_{3}$, whereas it also decreases the hydrogenation ability of the catalyst and inhibits the further hydrogenation of acetol into 1,2-PDO. In a reactor with double-layered catalysts, Ag-modified $\mathrm{Cu} / \mathrm{Al}_{2} \mathrm{O}_{3}$ is loaded on the upper layer of the catalyst bed to inhibit ethylene glycol formation and $\mathrm{Cu} / \mathrm{Al}_{2} \mathrm{O}_{3}$ without $\mathrm{Ag}$ is loaded on the lower layer to complete the acetol hydrogenation into 1,2-PDO: a $98.3 \%$ yield of 1,2-PDO is achieved over the double-layered catalysts at gradient temperatures from 170 to $105^{\circ} \mathrm{C}$.

In the vapor-phase hydrogenolysis of glycerol over $\mathrm{Cu} / \mathrm{SiO}_{2}$ prepared by an incipient wetness method, $87.0 \%$ selectivity to $1.2-\mathrm{PDO}$ is achieved with a complete glycerol conversion at $255{ }^{\circ} \mathrm{C}$ and an $\mathrm{H}_{2}$ pressure of 15 atm [119]. Zhu et al. modified $\mathrm{Cu} / \mathrm{SiO}_{2}$ with $\mathrm{B}_{2} \mathrm{O}_{3}$ and found that 
the addition of $\mathrm{B}_{2} \mathrm{O}_{3}$ into $\mathrm{Cu} / \mathrm{SiO}_{2}$ could greatly restrain the growth of copper particles and maintain the dispersion of copper species upon calcination, reduction and reaction during the vapor-phase glycerol hydrogenolysis [120]. The addition of suitable $\mathrm{B}_{2} \mathrm{O}_{3}$ to $\mathrm{Cu} / \mathrm{SiO}_{2}$ significantly enhances the catalytic activity, catalytic stability and 1,2-PDO selectivity: a 98.0\% selectivity to 1,2-PDO with a complete glycerol conversion is obtained over $\mathrm{Cu}-\mathrm{B}_{2} \mathrm{O}_{3} / \mathrm{SiO}_{2}$ catalyst at $200{ }^{\circ} \mathrm{C}$ and an $\mathrm{H}_{2}$ pressure of $50 \mathrm{~atm}$. Besides Cu-based catalysts, Ag- and Ru-based catalysts are also applied for the vapor-phase glycerol hydrogenolysis, whereas these catalysts do not show better catalytic performance than $\mathrm{Cu}$-based catalysts. In their further study, a $\mathrm{Cu} / \mathrm{SiO}_{2}$ catalyst is prepared by an ammonia evaporation hydrothermal method, and 1,2-PDO yield could be maintained at $c a .98 \%$ for $300 \mathrm{~h}$ at an $\mathrm{H}_{2}$ pressure of $50 \mathrm{~atm}$ [121]. Recently, they also reported a $\mathrm{Cu} / \mathrm{CeO}_{2}$ catalyst prepared by a solidstate grinding-assisted nanocasting method, which provides a stable yield of $c a$. 97\% [122]. The high performance of the $\mathrm{Cu} / \mathrm{SiO}_{2}$ and $\mathrm{Cu} / \mathrm{CeO}_{2}$ catalysts is explained to attribute the well dispersed $\mathrm{Cu}$ nanoparticles and the strong interaction between $\mathrm{Cu}$ and the supports. $\mathrm{Cu}-\mathrm{ZnO} / \mathrm{Al}_{2} \mathrm{O}_{3}$ catalyst are studied by several groups: the loading of $\mathrm{ZnO}$ promotes the formation of 1,2-PDO from glycerol, and 1,2-PDO selectivity higher than $90 \%$ can be achieved under $\mathrm{H}_{2}$ pressured conditions [124-126]. In a recent study, Harisekhar et al. studied Cu/SBA-15 catalyst, which gives a 84\% selectivity to $1,2-\mathrm{PDO}$ at $90 \%$ conversion at $200{ }^{\circ} \mathrm{C}$ under atmospheric $\mathrm{H}_{2}$ pressure [127]. Tanielyan et al. performed the reaction over various Raney catalysts such as Raney $\mathrm{Cu}, \mathrm{Cu}-\mathrm{Cr}$, and $\mathrm{Cu}-\mathrm{Cr}-\mathrm{Ni}$ $[79,80]$. Among the tested catalysts, Raney $\mathrm{Cu}$ shows the highest stability and gives the highest selectivity to 1,2-PDO. In a long run, higher than 95\% yield of 1,2,-PDO can be kept in 6.2 days. Ag catalyst supported on octahedral molecular sieve (OMS-2) gives an initial glycerol conversion of $c a$. $65 \%$ and 1,2-PDO selectivity of $c a .90 \%$ at $200{ }^{\circ} \mathrm{C}$ and an $\mathrm{H}_{2}$ pressure of 50 atm [128]. However, the catalyst gradually deactivates with time on stream: after $92 \mathrm{~h}$, the conversion and 1,2-PDO selectivity decreases to $c a$. 30 and $65 \%$, respectively. The decrease in the 1,2-PDO selectivity is caused by the decrease of hydrogenation ability of the catalyst: the selectivity to acetol increases up to $30 \%$ at a TOS of $92 \mathrm{~h}$. Vanama et al. studied vapor-phase glycerol hydrogenolysis over $\mathrm{Ru} / \mathrm{MCM}-41$ catalyst [129]. Because of the high hydrogenolysis ability of $\mathrm{Ru}, 1,2-\mathrm{PDO}$ further hydrogenates into lower alcohols such as 1-propanol and 2-propanol, and the maximum 1,2-PDO 
selectivity is only $38 \%$ at $230{ }^{\circ} \mathrm{C}$ under atmospheric $\mathrm{H}_{2}$ pressure. The low 1,2-PDO selectivity also ascribes to the competitive formation of 1,3-PDO and the by-production of ethylene glycol.

Table 5 Vapor-phase glycerol hydrogenolysis into 1,2-PDO.

\begin{tabular}{|c|c|c|c|c|c|c|c|}
\hline Catalyst & $\begin{array}{l}\text { Temp. } \\
\left({ }^{\circ} \mathrm{C}\right)\end{array}$ & $\begin{array}{l}\text { Pressure } \\
\text { (atm) }\end{array}$ & $\begin{array}{l}\text { WHSV } \\
\left(\mathrm{h}^{-1}\right)\end{array}$ & TOS & Conversion & $\begin{array}{c}\text { Selectivity to } \\
\text { 1,2-PDO } \\
(\%)\end{array}$ & Ref. \\
\hline $\mathrm{Cu} / \mathrm{Al}_{2} \mathrm{O}_{3}$ & $200-130^{\mathrm{a}}$ & 1 & 0.06 & $1-5^{b}$ & 100 & 96.1 & 74 \\
\hline $\mathrm{Ag}-\mathrm{Cu} / \mathrm{Al}_{2} \mathrm{O}_{3}$ & $170-105^{\mathrm{a}}$ & 1 & 0.03 & $1-5^{b}$ & 100 & 98.3 & 77 \\
\hline Raney $\mathrm{Cu}$ & 205 & 14 & 0.18 & $6.2^{\mathrm{d}}$ & 100 & 95 & 80 \\
\hline $\mathrm{Cu} / \mathrm{SiO}_{2}$ & 255 & 15 & 2.2 & unclear & 100 & 87 & 119 \\
\hline Copper-Chromite & 200 & 1 & 0.04 & 0.5 & 100 & 55.5 & 117 \\
\hline $\mathrm{Cu}-\mathrm{B}_{2} \mathrm{O}_{3} / \mathrm{SiO}_{2}$ & 200 & 50 & 0.08 & 56 & 100 & 98 & 120 \\
\hline $\mathrm{Cu} / \mathrm{SiO}_{2}$ & 200 & 50 & 0.08 & 300 & 100 & 98.3 & 121 \\
\hline $\mathrm{Cu} / \mathrm{CeO}_{2}$ & 180 & 50 & 0.15 & 300 & 100 & 96.9 & 122 \\
\hline $\mathrm{Cu}-\mathrm{ZnO} / \mathrm{Al}_{2} \mathrm{O}_{3}$ & 190 & 6.4 & 0.08 & unclear & 96.2 & 92.2 & 124 \\
\hline $\mathrm{Cu}-\mathrm{ZnO} / \mathrm{Al}_{2} \mathrm{O}_{3}$ & 250 & 32 & 2.8 & 12 & 100 & $>90$ & 125 \\
\hline $\mathrm{Cu}-\mathrm{ZnO} / \mathrm{Al}_{2} \mathrm{O}_{3}$ & 250 & 1 & 0.05 & 48.5 & 85.5 & 83.7 & 126 \\
\hline $\mathrm{Cu} / \mathrm{SBA}-15$ & 220 & 1 & 1.03 & 10 & 90 & 84 & 127 \\
\hline $\mathrm{Ag} / \mathrm{OMS}-2^{\mathrm{c}}$ & 200 & 50 & unclear & 92 & ca. 30 & ca. 65 & 128 \\
\hline Ru/MCM-41 & 230 & 1 & 2.09 & 10 & 62 & 38 & 129 \\
\hline
\end{tabular}

${ }^{\mathrm{a}}$ Gradient temperature. ${ }^{\mathrm{b}}$ Averaged activity between 1 to $5 \mathrm{~h} .{ }^{\mathrm{c}}$ OMS-2, octahedral molecular sieve. ${ }^{\mathrm{d}}$ Time on stream of 6.2 days.

Fig. 6 depicts equilibrium constants, $\mathrm{K}_{\mathrm{p}}$, in the hydrogenation of acetol at different temperatures. The closed and open triangles present the equilibrium constants of acetol hydrogenation in the reaction of glycerol hydrogenolysis and acetol hydrogenation, respectively, calculated from the data in our previous study [74]. The $K_{p}$ values are fitted to a master curve, as 
shown in Fig. 6. The $\mathrm{K}_{\mathrm{p}}$ values decreases with increasing the temperature, which indicates that the reaction is exothermic. Under gradient temperature conditions [74,77], after the dehydration of glycerol has proceeded at higher temperatures of the upper layer of the catalyst bed, low bottom temperatures would work to shift the equilibrium to the right side. Sato et al. have discussed chemical equilibrium in the dehydrogenation of 1,2-PDO to acetol, in which the equipment constant is estimated to be $0.15 \mathrm{~atm}$ at $210^{\circ} \mathrm{C}[123]$. Because the $\mathrm{K}_{\mathrm{p}}$ in the hydrogenation of acetol is equal to the reciprocal of the equilibrium constant in the dehydrogenation of 1,2-PDO, the equilibrium constant in the hydrogenation of acetol is $6.7 \mathrm{~atm}^{-1}$ at $210{ }^{\circ} \mathrm{C}$. The estimated $\mathrm{K}_{\mathrm{p}}$ value of acetol hydrogenation is close to the master curve in Fig. 6, which strongly supports that the hydrogenation of acetol achieves equilibrium at gradient temperatures [74]. $\mathrm{K}_{\mathrm{p}}$ values are calculated from several reference data at $100 \%$ conversion, and plotted in Fig. 6 . The $\mathrm{K}_{\mathrm{p}}$ values calculated from the data in Refs. $[77,119,120]$ are close to the master curve, which indicates that the hydrogenation of acetol formed from glycerol achieves equilibrium in these studies. Because the selectivities to acetol are not shown in Refs. [121, 122], $\mathrm{K}_{\mathrm{p}}$ values are not calculated for the reports. A $\mathrm{K}_{\mathrm{p}}$ value calculated from Ref. [80], however, is located above the master curve. Because the large amount, $16.5 \mathrm{~g}$, of catalyst is used in the study, it is plausible that the bottom temperature of the catalyst bed could be lower than the monitored temperature. On the other hand, the $K_{p}$ value calculated from Ref. [117] is located below the master curve, which indicates that equilibrium is not achieved possibly. 


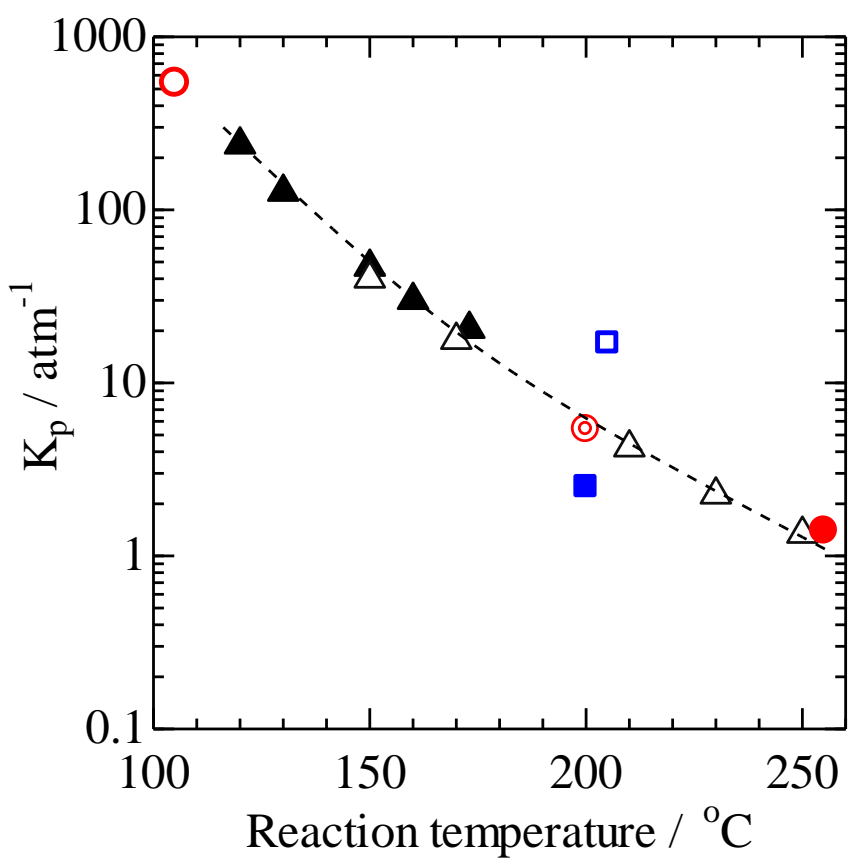

Figure 6 Changes in equilibrium constants of acetol hydrogenation with temperature.

Closed triangles present the equilibrium constants of acetol hydrogenation in the reaction of glycerol hydrogenolysis from Ref. [74]. Open triangles represent the equilibrium constants of acetol hydrogenation in the reaction of acetol hydrogenation from Ref [74]. Open, closed, and double circles represent the equilibrium constants of acetol hydrogenation in glycerol hydrogenolysis calculated from the data in Table 5 cited from Refs. [77,119,120], respectively. Open and closed squares are from those in Refs. [80, 117], respectively.

Cu-based catalysts show stable high activity toward 1,2-PDO formation in vapor-phase glycerol hydrogenolysis, and yields of 1,2-PDO over 96\% have been achieved in some studies [74,77,117]. Although a high $\mathrm{H}_{2}$ pressure is generally used for shifting the equilibrium from acetol to 1,2-PDO, acetol can be efficiently hydrogenated into 1,2-PDO even at an ambient $\mathrm{H}_{2}$ pressure and gradient temperatures in a vapor-phase reaction [74,77]. Comparing with liquid-phase reactions, vapor-phase reactions can achieve both high conversion and high 1,2-PDO selectivity. As mentioned in Sections 2.2-2.4, the consecutive reactions of dehydration and hydrogenation proceed in liquid-phase reactions to decrease the 1,2-PDO selectivity, especially when using acidic supports. However, 1,2-PDO does not further dehydrate over acidic supports even in vapor-phase reactions at relatively low temperatures as $200{ }^{\circ} \mathrm{C}$. Furthermore, the catalytic activity of $\mathrm{Cu}$-based catalysts is 
stable in a vapor phase $[74,77,117]$. Thus, from a view point of achieving high 1,2-PDO yield and inhibiting the formation of by-products, the vapor-phase reactions would be preferable in the selective glycerol hydrogenolysis into 1,2-PDO.

\section{1,3-Propanediol}

1,3-Propanediol (1,3-PDO) is commercially the most valuable product in the hydrogenolysis of glycerol. It is used in resins, engine coolants, dry-set mortars, water-based inks, but most of 1,3-PDO is used in the production of polypropylene terephthalate, which is a polyester synthesized from 1,3-PDO and terephthalic acid [5]. The market for 1,3-PDO is currently over $10^{5}$ tons per year, and the methods for producing 1,3-PDO are hydroformylation of ethylene oxide followed by hydrogenation, hydration of acrolein followed by hydrogenation, and fermentation of either glycerol or glucose [130]. The petroleum-based methods have a problem in selectivity, while the fermentation processes have a problem in production efficiency. Hydrogenolysis of glycerol to 1,3-PDO is an alternative process that could replace the current processes if efficient catalysts are developed. Although many attempts have been made to produce 1,3-PDO by hydrogenolysis of glycerol, the selectivity to 1,3-PDO is still unsatisfied for the industrial application.

Scheme 7 is the generally accepted reaction route of glycerol hydrogenolysis into 1,3-PDO. 1,3-PDO is produced by the hydrogenation of 3-hydroxypropanal [5,6], which is the dehydration product of glycerol. Thus, an acid catalyst is necessary in the first step of glycerol dehydration. In particular, Brønsted acid sites are necessary for the formation of 3-hydroxypropanal from glycerol [5]. Another possible route of 1,3-PDO is proposed by Tomishige et al. [73] as mentioned in Section 2.1 (Fig. 1). 
$\overbrace{\mathrm{OH}} \stackrel{+\mathrm{H}^{+}}{\longrightarrow}$

Glycerol<smiles></smiles>

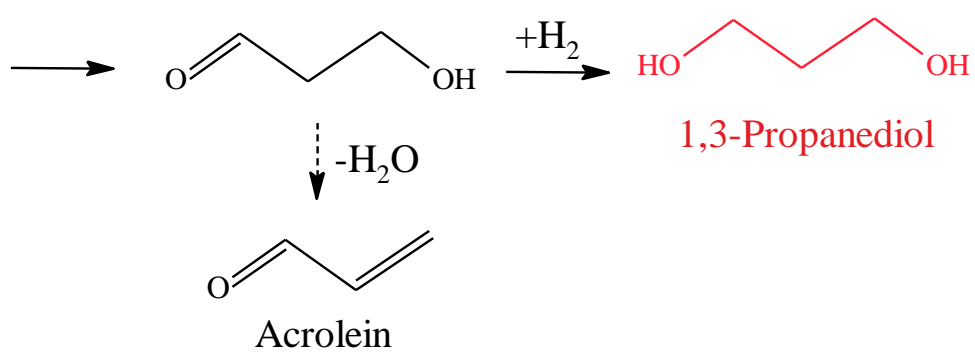

Scheme 7 Reaction routes of glycerol hydrogenolysis into 1,3-PDO [5].

\subsection{Hydrogenolysis of glycerol into 1,3-propanediol using a batch-type reactor}

Table 6 summarizes glycerol hydrogenolysis into 1,3-PDO performed in a batch-type reactor. Tomishige's group has performed a series of works dealing with glycerol hydrogenolysis into 1,3-PDO [6,73,131-134]. $\mathrm{SiO}_{2}$-supported precious metals with $\mathrm{ReO}_{\mathrm{x}}$ are found to be efficient for 1,3-PDO formation from glycerol, and Ir shows the highest catalytic activity among the precious metals such as $\mathrm{Rh}, \mathrm{Ru}, \mathrm{Pt}$, and $\mathrm{Pd}$. The yield of $1,3-\mathrm{PDO}$ is maximized at $38 \%$ over $\mathrm{Ir}-\mathrm{ReO} / \mathrm{SiO}{ }_{2}$ catalyst at $120{ }^{\circ} \mathrm{C}$ and an $\mathrm{H}_{2}$ pressure of 80 atm in the presence of $\mathrm{H}_{2} \mathrm{SO}_{4}$. The conversion of glycerol increases with increasing the reaction time, whereas the selectivity to 1,3-PDO decreases with increasing the reaction time because 1,3-PDO further converts into 1-propanol and propane. The maximum yield of 1,3-PDO is obtained at a reaction time of $36 \mathrm{~h}$ : the conversion of glycerol and the selectivity to $1,3-\mathrm{PDO}$ are $81 \%$ and $46 \%$, respectively. The relatively low reaction temperature is indicated to be significant for inhibiting the side reactions and increasing the 1,3-PDO selectivity. The $\mathrm{H}_{2}$ pressure affects the reaction rate, while $\mathrm{H}_{2}$ pressure rarely affects the selectivity to 1,3-PDO. Recently, mesoporous silica (KIT-6) supported Ir-Re alloy catalysts are applied for the glycerol hydrogenolysis in the presence of amberlyst-15 as an acidic promoter at the same reaction conditions [135]. 
Table 6 Hydrogenolysis of glycerol into 1,3-propanediol using a batch-type reactor.

\begin{tabular}{|c|c|c|c|c|c|c|c|c|}
\hline Catalyst & $\begin{array}{l}\text { Temp. } \\
\left({ }^{\circ} \mathrm{C}\right)\end{array}$ & $\begin{array}{c}\mathrm{H}_{2} \\
\text { pressure } \\
\text { (atm) }\end{array}$ & Solvent & $\begin{array}{c}\text { Glycerol/C } \\
\text { atalyst } \\
\text { (g/g) }\end{array}$ & $\begin{array}{l}\text { Time } \\
\text { (h) }\end{array}$ & $\begin{array}{c}\text { Conversion } \\
\text { of glycerol } \\
(\%)\end{array}$ & $\begin{array}{c}\text { Selectivity to } \\
\text { 1,3-PDO } \\
(\%)\end{array}$ & Ref. \\
\hline $\mathrm{Ir}-\mathrm{ReO}_{x} / \mathrm{SiO}_{2}$ & 120 & 80 & $\mathrm{H}_{2} \mathrm{O}$ & 26.7 & 36 & 81 & 46 & 131 \\
\hline $\mathrm{Rh}-\mathrm{ReO}_{\mathrm{x}} / \mathrm{SiO}_{2}$ & 120 & 80 & $\mathrm{H}_{2} \mathrm{O}$ & 26.7 & 5 & ca. 42 & ca. 20 & 132 \\
\hline Ir-Re alloy/KIT-6 ${ }^{\mathrm{a}}$ & 120 & 80 & $\mathrm{H}_{2} \mathrm{O}$ & 26.7 & 12 & 63.3 & 34.7 & 135 \\
\hline $\mathrm{Pt}-\mathrm{WO}_{3} / \mathrm{ZrO}_{2}$ & 170 & 80 & $\mathrm{DMI}^{\mathrm{c}}$ & 2.8 & 18 & 85.8 & 28.2 & 136 \\
\hline $\mathrm{Pt} / \mathrm{WO}_{3}-\mathrm{TiO}_{2} / \mathrm{SiO}_{2}$ & 180 & 55 & $\mathrm{H}_{2} \mathrm{O}$ & $2^{\mathrm{b}}$ & 12 & 15.3 & 50.5 & 137 \\
\hline $\mathrm{Pt} / \mathrm{WO}_{\mathrm{x}}-\mathrm{TiO}_{\mathrm{x}}$ & 180 & 55 & $\mathrm{H}_{2} \mathrm{O}$ & 4 & 12 & 18.4 & 40.3 & 138 \\
\hline $\mathrm{Pt}-\mathrm{AlO}_{\mathrm{x}} / \mathrm{WO}_{\mathrm{x}}$ & 180 & 30 & $\mathrm{H}_{2} \mathrm{O}$ & 0.9 & 10 & 90 & 44 & 139 \\
\hline $\mathrm{Pt}-\mathrm{WO}_{\mathrm{x}} / \mathrm{AlOOH}$ & 180 & 50 & $\mathrm{H}_{2} \mathrm{O}$ & 0.9 & 12 & 100 & 66 & 140 \\
\hline $\mathrm{Pt}-\mathrm{WO}_{\mathrm{x}} / \mathrm{Al}_{2} \mathrm{O}_{3}$ & 180 & 50 & $\mathrm{H}_{2} \mathrm{O}$ & 0.9 & 12 & 89 & 35 & 140 \\
\hline $\mathrm{Pt}-\mathrm{WO}_{\mathrm{x}} / \mathrm{Al}_{2} \mathrm{O}_{3}$ & 200 & 40 & $\mathrm{H}_{2} \mathrm{O}$ & 4.7 & 18 & 49 & 28 & 141 \\
\hline $\mathrm{Pt}-\mathrm{WO}_{\mathrm{x}} / \mathrm{Al}_{2} \mathrm{O}_{3}$ & 200 & 45 & $\mathrm{H}_{2} \mathrm{O}$ & 6.1 & 24 & 51.9 & 53.1 & 142 \\
\hline $\mathrm{Pt} /$ Sulfated $\mathrm{ZrO}_{2}$ & 170 & 73 & $\mathrm{DMI}^{\mathrm{c}}$ & 2.8 & 24 & 66.5 & 83.6 & 141 \\
\hline
\end{tabular}

${ }^{a}$ KIT-6, mesoporous silica. ${ }^{b}$ Volume ratio of glycerol/ catalyst. ${ }^{c}$ DMI: 1,3-dimethyl-2-imidazolidinone.

Pt and tungsten oxide as an acidic modifier are reported to accelerate the formation of 1,3-PDO from glycerol. Kurosaka et al. have studied glycerol hydrogenolysis into 1,3-PDO in the pioneering report [136]. A 24\% yield of 1,3-PDO is obtained from glycerol at $170{ }^{\circ} \mathrm{C}$ and an $\mathrm{H}_{2}$ pressure of 80 atm over $\mathrm{Pt}-\mathrm{WO}_{3} / \mathrm{ZrO}_{2}$ catalyst, in which $\mathrm{ZrO}_{2}$-supported $\mathrm{WO}_{3}$ is well known as a super acid. Besides Pt, other precious metals such as $\mathrm{Pd}, \mathrm{Ru}, \mathrm{Rh}$, and Ir are not active for 1,3-PDO formation and give 1,3-PDO yields lower than 5\%. Gong et al. have investigated the glycerol hydrogenolysis over $\mathrm{Pt} / \mathrm{WO}_{3}-\mathrm{TiO}_{2} / \mathrm{SiO}_{2}$ catalyst [137]. $\mathrm{WO}_{3}$ species are concluded to regulate the acidity of the $\mathrm{Pt} / \mathrm{WO}_{3}-\mathrm{TiO}_{2} / \mathrm{SiO}_{2}$ catalyst by producing Brønsted acid sites, which play a key role during 1,3-PDO formation, and the existence of $\mathrm{TiO}_{2}$ species improves the dispersion of Pt metal. It 
is supposed that the Brønsted acid sites on $\mathrm{WO}_{3}$ surface catalyze the dehydration of glycerol to 3-hydroxypropanal, and the highly dispersed Pt particles catalyze the further hydrogenation of 3-hydroxypropanal to 1,3-PDO as shown in Fig 7. The selectivity to 1,3-PDO is maximized at $50.5 \%$ at $180{ }^{\circ} \mathrm{C}$ and an $\mathrm{H}_{2}$ pressure of 55 atm, whereas the conversion of glycerol is as low as 15.3\%. In a recent report, $\mathrm{Pt}$ supported on mesoporous $\mathrm{WO}_{\mathrm{x}}-\mathrm{TiO}_{\mathrm{x}}$ shows similar results of reactions using $\mathrm{Pt} / \mathrm{WO}_{3}-\mathrm{TiO}_{2} / \mathrm{SiO}_{2}[138]$.

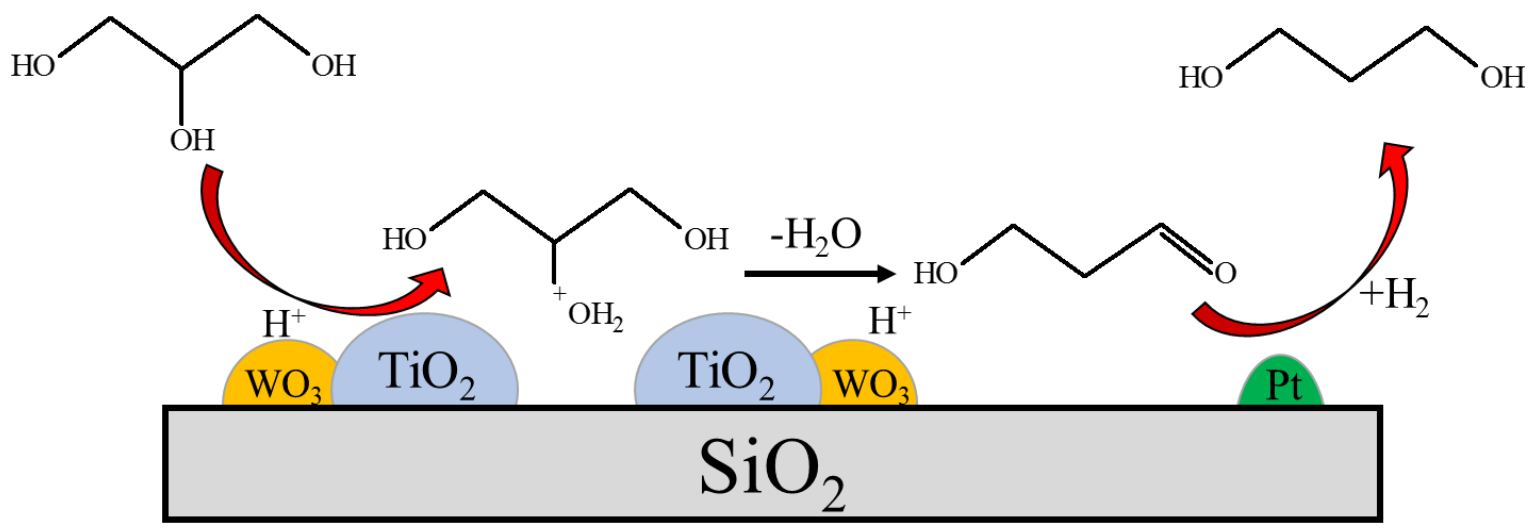

Figure 7 Proposed mechanism of glycerol hydrogenolysis to 1,3-PDO over $\mathrm{Pt} / \mathrm{WO}_{3}-\mathrm{TiO}_{2} / \mathrm{SiO}_{2}$ catalyst [137].

Kaneda's group has studied the glycerol hydrogenolysis using $\mathrm{WO}_{\mathrm{x}}$-supported $\mathrm{Pt}-\mathrm{AlO}_{\mathrm{x}}$ catalyst, and 44\% 1,3-PDO selectivity with a high glycerol conversion of $90 \%$ is achieved at $180{ }^{\circ} \mathrm{C}$ under a relatively low $\mathrm{H}_{2}$ pressure of 30 atm without any acidic additives [139]. In their study, boehmite-supported $\mathrm{Pt} / \mathrm{WO}_{\mathrm{x}}$ shows much better catalytic performance and gives a 1,3-PDO yield of $66 \%$, which is the highest value reported ever before, at $180{ }^{\circ} \mathrm{C}$ and an $\mathrm{H}_{2}$ pressure of $50 \mathrm{~atm}$ [140]. They have also performed the hydrogenolysis of some diols, such as 1,3-PDO, 1,2-PDO, 1,2-butanediol, and 2,3-butanediol, over $\mathrm{Pt} / \mathrm{WO}_{\mathrm{x}} / \mathrm{AlOOH}$, and found that 1,2-PDO and 1,2-butanediol are much more reactive than 1,3-PDO and 2,3-butanediol. They conclude that $\mathrm{Pt}-\mathrm{WO}_{\mathrm{x}} / \mathrm{AlOOH}$ has high activity for the secondary $\mathrm{OH}$ group adjacent to a primary $\mathrm{OH}$ group. Consequently, both high glycerol conversion and high 1,3-PDO selectivity is obtained because 1,3-PDO is less reactive over $\mathrm{Pt} / \mathrm{WO}_{\mathrm{x}} / \mathrm{AlOOH}$. The catalyst is also stable and can be reused for 3 
times without deactivation. Comparing with $\mathrm{AlOOH}$-supported $\mathrm{Pt}-\mathrm{WO}_{\mathrm{x}}, \mathrm{Al}_{2} \mathrm{O}_{3}$-support $\mathrm{Pt}-\mathrm{WO}_{\mathrm{x}}$ catalyst shows both low glycerol conversion and low 1,3-PDO selectivity [140-142], and they propose that the large quantity of $\mathrm{Al}-\mathrm{OH}$ groups on the surface of the $\mathrm{Al}_{2} \mathrm{O}_{3}$ enhances its catalytic activity.

Oh et al. reported selective formation of 1,3-PDO from glycerol using Pt/sulfated $\mathrm{ZrO}_{2}$ catalyst, in which sulfated zirconia is a well-known super acid [143]. An extremely high 1,3-PDO selectivity of $83.6 \%$ at a glycerol conversion of $66.5 \%$ is achieved in 1,3-dimethyl-2-imidazolidinone (DMI) solvent at $170{ }^{\circ} \mathrm{C}$ and an $\mathrm{H}_{2}$ pressure of $73 \mathrm{~atm}$. It is interesting that when DMI is replaced by water, the selectivity to $1,3-\mathrm{PDO}$ is only $19.6 \%$. Thus, DMI probably plays an essential role on the 1,3-PDO formation.

\subsection{Hydrogenolysis of glycerol into 1,3-propanediol using a flow-type reactor}

Table 7 summarizes vapor-phase hydrogenolysis of glycerol into 1,3-PDO using a flow-type reactor [144-150]. Huang et al. firstly reported glycerol hydrogenolysis into 1,3-PDO over non-precious metal catalysts in a flow-type reactor [144]. $\mathrm{SiO}_{2}$-supported $\mathrm{Cu}-\mathrm{H}_{4} \mathrm{SiW}_{12} \mathrm{O}_{40}$ catalyst gives a maximum 1,3-PDO selectivity of $32.1 \%$ at $83.4 \%$ conversion. The effects of reaction temperatures, $\mathrm{H}_{2}$ pressures, and WHSV are investigated in detail: high reaction temperatures promote the conversion of glycerol, but decrease the selectivity to 1,3-PDO because of the competitive formation of decomposed products at high temperatures; high $\mathrm{H}_{2}$ pressures are efficient for achieving both high glycerol conversion and 1,3-PDO selectivity; the conversion of glycerol increases with decreasing the WHSV, whereas the selectivity to both 1,3-PDO and 1,2-PDO decreases because the produced diols further convert into cyclic acetals for a long residence time. Qin et al. studied glycerol hydrogenolysis into 1,3-PDO using $\mathrm{Pt}-\mathrm{WO}_{3} / \mathrm{ZrO}_{2}$ catalyst which gives 45.6\% 1,3-PDO selectivity at 70.2\% conversion at $130{ }^{\circ} \mathrm{C}$ and an $\mathrm{H}_{2}$ pressure of $40 \mathrm{~atm}$ [145]. The effects of reaction temperatures and $\mathrm{H}_{2}$ pressures are studied and the conclusions agree with those in the reports of Huang et al. mentioned above [144]. 
Table 7 Hydrogenolysis of glycerol into 1,3-propanediol using a flow-type reactor.

\begin{tabular}{|c|c|c|c|c|c|c|c|}
\hline Catalyst & $\begin{array}{l}\text { Temp. } \\
\left({ }^{\circ} \mathrm{C}\right)\end{array}$ & $\begin{array}{c}\mathrm{H}_{2} \\
\text { pressure } \\
\text { (atm) }\end{array}$ & $\begin{array}{c}\text { WHSV } \\
\left(\mathrm{h}^{-1}\right)\end{array}$ & $\begin{array}{l}\text { TOS } \\
\text { (h) }\end{array}$ & $\begin{array}{l}\text { Conversion } \\
\text { of glycerol } \\
(\%)\end{array}$ & $\begin{array}{c}\text { Selectivity to } \\
\begin{array}{c}\text { 1,3-PDO } \\
(\%)\end{array}\end{array}$ & Ref. \\
\hline $\mathrm{Cu}-\mathrm{H}_{4} \mathrm{SiW}_{12} \mathrm{O}_{40} / \mathrm{SiO}_{2}$ & 210 & 5.4 & 0.1 & unclear & 83.4 & 32.1 & 144 \\
\hline $\mathrm{Pt}-\mathrm{WO}_{3} / \mathrm{ZrO}_{2}$ & 130 & 40 & $0.25^{\mathrm{a}}$ & 24 & 70.2 & 45.6 & 145 \\
\hline $\mathrm{Pt}-\mathrm{WO}_{\mathrm{x}}-\mathrm{SiO}_{2} / \mathrm{ZrO}_{2}$ & 180 & 50 & 0.1 & unclear & 54.3 & 52 & 146 \\
\hline $\mathrm{Cu}-\mathrm{H}_{4} \mathrm{SiW}_{12} \mathrm{O}_{40} / \mathrm{ZrO}_{2}$ & 180 & 50 & 0.1 & unclear & 24.1 & 48.1 & 147 \\
\hline $\mathrm{Pt}-\mathrm{Li}_{2} \mathrm{H}_{2} \mathrm{SiW}_{12} \mathrm{O}_{40} / \mathrm{ZrO}_{2}$ & 180 & 50 & 0.1 & 120 & 43.5 & 53.6 & 148 \\
\hline $\mathrm{Pt}-\mathrm{WO}_{\mathrm{x}} / \mathrm{Al}_{2} \mathrm{O}_{3}$ & 160 & 50 & 0.1 & unclear & 64.2 & 66.1 & 149 \\
\hline $\mathrm{Pt} / \mathrm{AlPO}_{4}$ & 260 & 1 & 2.1 & 4 & 100 & 35.4 & 150 \\
\hline
\end{tabular}

${ }^{\mathrm{a}}$ LHSV value

In a recent study, Zhu et al. have prepared $\mathrm{SiO}_{2}$-modified $\mathrm{Pt}-\mathrm{WO}_{\mathrm{x}} / \mathrm{ZrO}_{2}$ catalyst which gives an improved 1,3-PDO selectivity of 52\% [146]: the addition of $\mathrm{SiO}_{2}$ enhances $\mathrm{Pt}$ dispersion and acidity, which leads to the improved activity and 1,3-PDO selectivity. Zhu's group has also performed the glycerol hydrogenolysis using $\mathrm{Cu}-\mathrm{H}_{4} \mathrm{SiW}_{12} \mathrm{O}_{40} / \mathrm{ZrO}_{2}$ [147], $\mathrm{Pt}_{-}-\mathrm{Li}_{2} \mathrm{H}_{2} \mathrm{SiW}_{12} \mathrm{O}_{40} / \mathrm{ZrO}_{2}$ [148] and Pt- $\mathrm{WO}_{\mathrm{x}} / \mathrm{Al}_{2} \mathrm{O}_{3}$ catalysts [149], and study the effect of the acid property on the 1,3-PDO formation. It is found that the yield of 1,3-PDO is proportional to the concentration of the Brønsted acid sites, while the yield of 1,2-PDO is proportional to the concentration of Lewis acid sites [149]. Thus, the existence of the large amount of Brønsted acid sites on the support are significant for the selective hydrogenolysis of glycerol to 1,3-PDO. The highest 1,3-PDO yield of $42 \%$ is achieved over Pt- $\mathrm{WO}_{\mathrm{x}} / \mathrm{Al}_{2} \mathrm{O}_{3}$ catalyst at $160{ }^{\circ} \mathrm{C}$ and an $\mathrm{H}_{2}$ pressure of $50 \mathrm{~atm}$. Priya et al. have studied the glycerol hydrogenolysis over $\mathrm{Pt} \mathrm{AlPO}_{4}$ catalyst at atmospheric $\mathrm{H}_{2}$ pressure [150,151]. The selectivity to $1,3-\mathrm{PDO}$ is maximized at $35.4 \%$ at $260{ }^{\circ} \mathrm{C}$ with a complete glycerol conversion. However, the analysis of gas products and the information of recovery are not mentioned although it is reasonable that decomposition of products is possible at high reaction temperatures. 


\subsection{General summary of glycerol hydrogenolysis into 1,3-propanediol}

The property of acid promoter is a key for the 1,3-PDO formation from glycerol. As summarized in Tables 6 and 7, high 1,3-PDO selectivity can be obtained in the presence of strong Brønsted acid sites, and the reaction temperature is generally lower than that for 1,2-PDO formation. Acetol, which can be further hydrogenated into 1,2-PDO (Scheme 4), and 3-hydroxypropanal that can be further hydrogenated into 1,3-PDO (Scheme 7) are two determinate intermediates in the glycerol hydrogenolysis. In another word, the formation of 1,2-PDO and 1,3-PDO is competitive and thus the selectivity to 1,2-PDO and 1,3-PDO is determined by which intermediate, acetol, or 3-hydroxypropanal, is preferentially produced from glycerol. Glycerol dehydration into acetol generally prefers either metal active sites [74-78] or Lewis acid sites [149] at high reaction temperatures are preferable. On the other hand, glycerol dehydration into 3-hydroxypropanal prefers Brønsted acid sites [149]. Although high reaction temperatures accelerate the glycerol dehydration into 3-hydroxypropanal, they also promote the further dehydration of 3-hydroxypropanal into acrolein. Thus, relatively low reaction temperatures are efficient for inhibiting the further dehydration of 3-hydroxypropanal into acrolein, and 1,3-PDO can be produced via the hydrogenation of 3-hydroxypropanal. Additionally, strong Brønsted acid sites are necessary for the hydrogenolysis of glycerol into 1,3-PDO because they can catalyze the hydrogenolysis of glycerol into 3-hydroxypropanal at lower reaction temperatures than weak and medium Brønsted acid sites. Therefore, a successful catalyst system for the selective transformation of glycerol into 1,3-PDO requires to minimize the side reaction of 3-hydroxypropanal dehydration into acrolein as well as to promote the coupled dehydration-hydrogenation reactions.

It is reasonable that it is difficult to produce 1,3-PDO selectively because 1,3-PDO is easily further converted into 1-propanol in addition to the unstable intermediate such as 3-hydroxypropanal [5,6]. The reactivity of 1,3-PDO is higher than 1,2-PDO in most catalyst

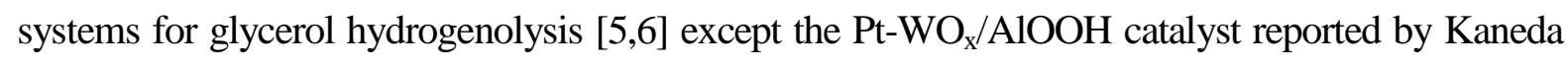
et al. [140]. Glycerol hydrogenolysis into 1,3-PDO requires low reaction temperatures and high $\mathrm{H}_{2}$ pressures to promote the hydrogenation of 3-hydroxypropanal. In a flow-type reactor under the conditions at a low temperature and a high $\mathrm{H}_{2}$ pressure, it is difficult to vaporize a less volatile 
glycerol [144-149]. In a liquid-phase reaction using a batch-type reactor at a low temperature, on the other hand, a high $\mathrm{H}_{2}$ pressure condition can be readily realized. In future studies, the development of a catalyst system, which is extremely active for 1,3-PDO formation from glycerol but inactive for the further conversion of 1,3-PDO, is considered as a big challenge.

\section{Monoalcohols and propylene}

As described in the previous sections, a large number of efforts have been conducted for producing 1,2-PDO and 1,3-PDO through glycerol hydrogenolysis. On the other hand, the further hydrogenolysis products from 1,2-PDO and 1,3-PDO, such as allyl alcohol, propanols, and propylene, are also attractive and valuable. In the last 5 years, many studies dealing with glycerol hydrogenolysis into these chemicals have been reported. Scheme 8 summarizes the reaction routes of multi-step hydrogenolysis of glycerol. Allyl alcohol is an important chemical intermediate due to the bi-functionality, such as a hydroxyl group and a C-C double bond in the molecule, and it has wide use for producing resins, paints, coatings, silane coupling agents, and polymers [152]. Propanols, such as 1-propanol and 2-propanol, have lower value than 1,3-PDO and 1,2-PDO, while they are also attractive chemicals available to be produced from glycerol. Both 1-propanol and 2-propanol have a wide array of solvent uses. In glycerol hydrogenolysis, 1-propanol can be produced via either 1,2-PDO, 1,3-PDO, or acrolein, while 2-propanol can be only produced via 1,2-PDO. Propylene, which is also an important starting resource in the petrochemical industry, can be produced from glycerol via both 1-propanol and 2-propanol dehydration. In this section, glycerol hydrogenolysis into allyl alcohol, propanols, and propylene are summarized and discussed. 


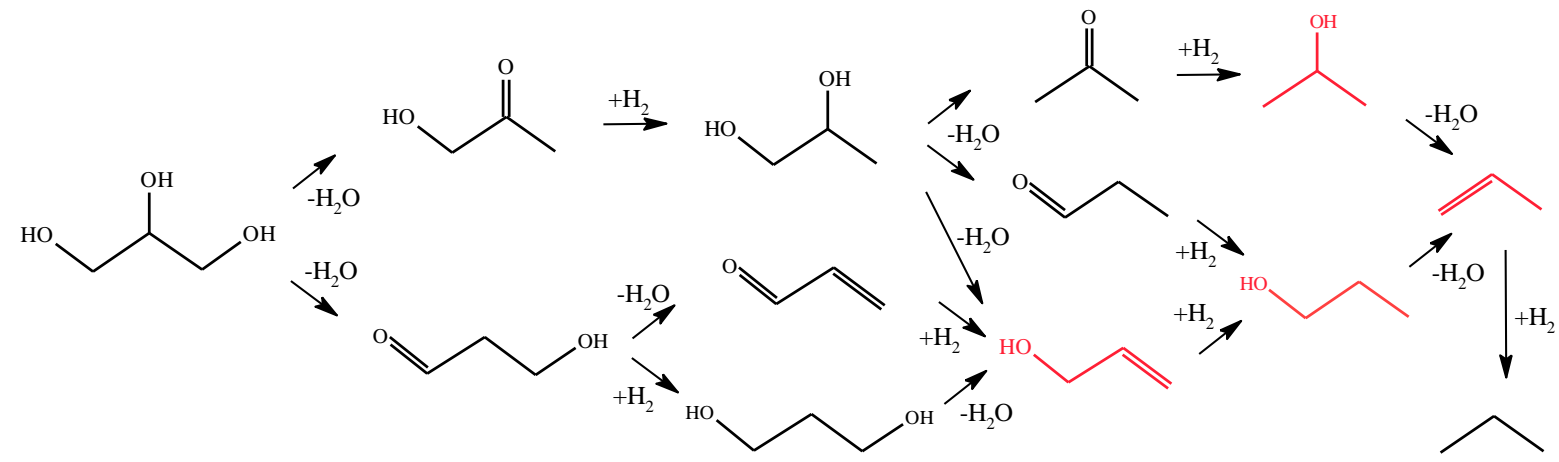

Scheme 8 Reaction routes of glycerol hydrogenolysis into allyl alcohol, propanols, and propylene.

\subsection{Allyl alcohol}

In Scheme 8, it is reasonable that allyl alcohol can be generated from glycerol via both 1,2-PDO and 1,3-PDO dehydration. However, selective synthesis of allyl alcohol from glycerol under $\mathrm{H}_{2}$ pressure conditions has not been reported. 1,2-PDO dehydration gives three kinds of products, such as acetone, propanal, and allyl alcohol (Scheme 8), whereas selective dehydration of 1,2-PDO into allyl alcohol is very difficult and has not been reported. Propanal is the main product in 1,2-PDO dehydration over acid catalysts, such as $\mathrm{H}_{4} \mathrm{SiW}_{12} \mathrm{O}_{40} / \mathrm{SiO}_{2}$ [153], $\mathrm{SiO}_{2}-\mathrm{Al}_{2} \mathrm{O}_{3}$ [154], and $\mathrm{WO}_{3} / \mathrm{SiO}_{2}$ [89], and the selectivity to allyl alcohol is lower than $5 \%[89,153,154]$. Allyl alcohol can be also generated from glycerol via 1,3-PDO dehydration and acrolein hydrogenation, whereas it is difficult to be selectively produced because it is easy to be further hydrogenated into 1-propanol under $\mathrm{H}_{2}$ pressure conditions. As a consequence, all the successful reports aimed to produce allyl alcohol from glycerol are performed through a hydrogen transfer reaction in which either monoalcohols or acids are used as the $\mathrm{H}$ donor instead of $\mathrm{H}_{2}$. 


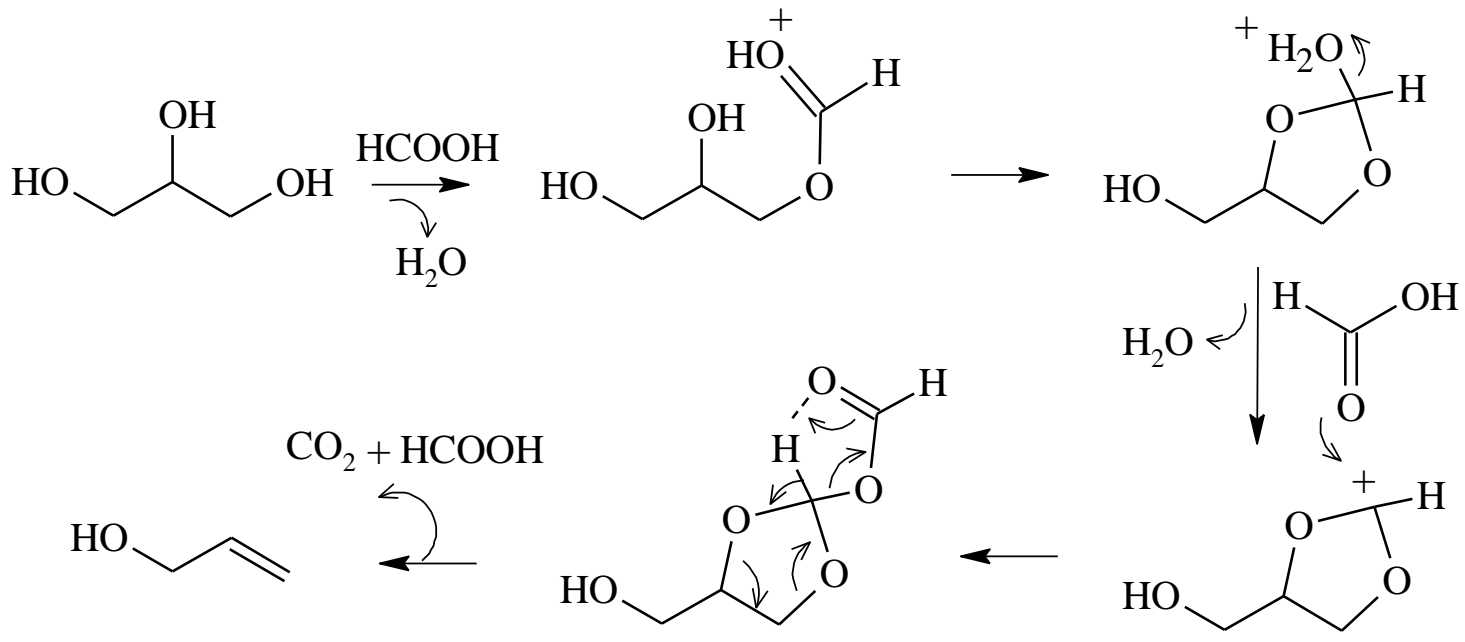

Scheme 9 Mechanism for the formic acid-mediated double dehydroxylation of glycerol into allyl alcohol proposed by Arceo et al. [155].

Table 8 summarizes liquid-phase glycerol hydrogenolysis into allyl alcohol through a hydrogen transfer reaction. Arceo et al. have performed glycerol hydrogenolysis by heating a mixture of glycerol and formic acid without other additives under reflux conditions $[155,156]$. Formic acid works as the $\mathrm{H}$ donor and also as the catalyst, and the proposed reaction mechanism is shown in Scheme 9. The maximum yield of allyl alcohol is $89 \%$, which is achieved at a heating temperature of $230-240{ }^{\circ} \mathrm{C}$. Oxorhenium-catalyzed deoxydehydration of sugars and sugar alcohols into olefins is investigated by Shiramizu et al. [157]. 3-Octanol is used as the $\mathrm{H}$ donor for glycerol hydrogenolysis and a 90\% yield of allyl alcohol is achieved over the methyltrioxorhenium (MTO) catalyst at $170{ }^{\circ} \mathrm{C}$. Yi et al. have also studied deoxydehydration of glycerol using oxorhenium-based catalysts, in which the reactions are performed using neat glycerol without any other additives [158]. Because a half of glycerol is consumed as the $\mathrm{H}$ donor and the maximum yield of allyl alcohol cannot exceed $50 \%$. The maximum yield of allyl alcohol is $38 \%$, which is achieved over $\mathrm{NaReO}_{4}$ catalyst at $165{ }^{\circ} \mathrm{C}$ in the presence of $\mathrm{NH}_{4} \mathrm{Cl}$, and the main by-product is 1,3-dihydroxyacetone, which is formed by glycerol dehydrogenation. 
Table 8 Liquid-phase glycerol hydrogenolysis into allyl alcohol through a hydrogen transfer reaction.

\begin{tabular}{cccccccc}
\hline Catalyst & Temp. & Pressure & Solvent & Glycerol/Catalyst & Time & Yield of AA $^{\mathrm{a}}$ & Ref. \\
& & & & & & & \\
& $\left({ }^{\circ} \mathrm{C}\right)$ & $(\mathrm{atm})$ & & $(\mathrm{g} / \mathrm{g})$ & $(\mathrm{h})$ & $(\%)$ & \\
\hline- & $230-240$ & 1 & formic acid & - & 3 & 89 & 155 \\
$\mathrm{MTO}^{\mathrm{b}}$ & 170 & 1 & 3-octanol & unclear & 2.5 & 90 & 157 \\
$\mathrm{NaReO}_{4}$ & 165 & 1 & Glycerol & 18.6 & 1 & 38 & 158 \\
\hline
\end{tabular}

${ }^{\mathrm{a}}$ AA, allyl alcohol. ${ }^{\mathrm{b}}$ MTO, methyltrioxorhenium.

Table 9 summarizes vapor-phase glycerol hydrogenolysis into allyl alcohol in $\mathrm{N}_{2}$ atmosphere using glycerol itself as the $\mathrm{H}$ donor. Liu et al. have performed the reaction over $\mathrm{Fe}_{2} \mathrm{O}_{3}$ catalyst using 35 wt.\% glycerol aqueous solution under $\mathrm{N}_{2}$ flow conditions [159]. Allyl alcohol is mainly produced at a selectivity of $20-25 \%$ at $320{ }^{\circ} \mathrm{C}$, and the selectivity to acrolein and acetol is 6-9\% and 18-20\%, respectively. Allyl alcohol is supposed to be produced via acrolein partial hydrogenation though a catalytic hydrogen transfer mechanism, and the intermediates with hydroxy groups together with glycerol are supposed to be the $\mathrm{H}$ donors. However, because the selectivity to the undetectable products is as high as ca. $40 \%$, it is also possible that an $\mathrm{H}_{2}$ molecule is generated in-situ by the catalytic reforming of glycerol. Masuda's group has conducted a series of works on glycerol conversion into useful chemicals containing allyl alcohol and propylene [152,160-162]. $\mathrm{ZrO}_{2}-\mathrm{FeO}_{\mathrm{x}}$ is firstly prepared and gives $\mathrm{ca}$. $20 \%$ selectivity to allyl alcohol at $350{ }^{\circ} \mathrm{C}$ using $50 \%$ glycerol aqueous solution as a reactant [160]. Besides allyl alcohol, many kinds of products are formed during the reaction: the selectivity to carboxylic acids (acetic acid and propionic acid), ketones (acetone and 2-butanone), and aldehydes (acrolein and acetaldehyde) is ca. 20, 10, and 10\%, respectively. In a recent study, $10 \mathrm{wt} . \%$ crude glycerol aqueous solution is used as the reactant, and $27 \%$ yield of allyl alcohol is achieved over $\mathrm{K}$-modified $\mathrm{ZrO}_{2}-\mathrm{FeO}_{\mathrm{x}}$ catalyst [152]. Because the modification of $\mathrm{K}$ decreases the acidic property but increases allyl alcohol yield, it is proposed that allyl alcohol is produced over non-acidic sites through a hydrogen transfer mechanism. It is also proposed that the hydrogen atoms are derived from formic acid which is formed by glycerol 
decomposition during the reaction. Sánchez et al. have studied glycerol conversion into allyl alcohol using alkali metal-modified $\mathrm{FeO}_{\mathrm{x}}-\mathrm{Al}_{2} \mathrm{O}_{3}$ catalysts, and $12 \%$ yield of allyl alcohol is obtained over $\mathrm{Rb} / \mathrm{FeO}_{\mathrm{x}}-\mathrm{Al}_{2} \mathrm{O}_{3}$ at $340{ }^{\circ} \mathrm{C}$ [163]. $\mathrm{FeO}_{\mathrm{x}}$ plays an important role for allyl alcohol formation from glycerol. Nevertheless, vapor-phase reaction over $\mathrm{FeO}_{\mathrm{x}}$-based catalyst systems requires a high reaction temperature, which results in many kinds of by-products. Therefore, in such a process, it is difficult to selectively produce allyl alcohol. The improvement of the catalyst system is considerable to be necessary for selective production of allyl alcohol in future studies.

Table 9 Vapor-phase glycerol hydrogenolysis into allyl alcohol using glycerol itself as the H donor.

\begin{tabular}{|c|c|c|c|c|c|c|c|c|}
\hline Catalyst & $\begin{array}{l}\text { Temp. } \\
\left({ }^{\circ} \mathrm{C}\right)\end{array}$ & $\begin{array}{l}\text { Pressure } \\
\left(\mathrm{N}_{2}\right) \\
(\mathrm{atm})\end{array}$ & $\mathrm{H}$ donor & $\begin{array}{l}\text { TOS } \\
\text { (h) }\end{array}$ & WHSV & $\begin{array}{l}\text { Conversion } \\
\text { of glycerol } \\
(\%)\end{array}$ & $\begin{array}{l}\text { Selectivity } \\
\text { to } \mathrm{AA}^{\mathrm{a}} \\
(\%)\end{array}$ & Ref. \\
\hline $\mathrm{Fe}_{2} \mathrm{O}_{3}$ & 320 & 1 & glycerol & 6 & 2.5 & 100 & 23 & 159 \\
\hline $\mathrm{ZrO}_{2}-\mathrm{FeO}_{\mathrm{x}}$ & 350 & 1 & glycerol & 6 & 1.0 & 100 & 20 & 160 \\
\hline $\mathrm{K} / \mathrm{ZrO}_{2}-\mathrm{FeO}_{\mathrm{x}}$ & 350 & 1 & glycerol & 6 & 0.2 & 100 & 27 & 162 \\
\hline $\mathrm{Rb} / \mathrm{FeO}_{\mathrm{x}}-\mathrm{Al}_{2} \mathrm{O}_{3}$ & 340 & 1 & glycerol & 3 & 0.3 & 89.8 & 13 & 163 \\
\hline
\end{tabular}

${ }^{\mathrm{a}} \mathrm{AA}$, allyl alcohol.

Generally, the selective hydrogenation of acrolein to allyl alcohol in an $\mathrm{H}_{2}$ atmosphere is difficult. However, some achievements have been obtained using Au- [164] and Ag-based catalysts [165-167]. An Ag-In/SiO 2 catalyst can give $61 \%$ selectivity to allyl alcohol at $97 \%$ conversion of acrolein at $240{ }^{\circ} \mathrm{C}$ under $20 \mathrm{~atm} \mathrm{H}_{2}$ pressure [167]. Thus, the development of combined catalysts, which contain both the proper acidity for glycerol dehydration to acrolein and the suitable hydrogenation activity for the partial hydrogenation of acrolein to allyl alcohol, is worthy to be attempted in a direct conversion of glycerol to allyl alcohol in an $\mathrm{H}_{2}$ atmosphere instead of using H-donor molecules. 


\subsection{Propanols}

Comparing with 2-propanol, it is easy to produce 1-propanol selectively from glycerol because 1,2-PDO, which is readily formed from glycerol, prefers to convert to 1-propanol rather than 2-propanol $[168,169]$. Table 10 summarizes the liquid-phase hydrogenolysis of glycerol into propanols. Xiao et al. have performed glycerol hydrogenolysis over copper chromite catalyst and studied the pathway of glycerol hydrogenolysis [170]. 1,2-PDO is the main product over copper chromite catalyst, and it further converts into 1-propanol and 2-propanol especially at high reaction temperatures and high $\mathrm{H}_{2}$ pressures for long reaction time. The selectivity to 1-propanol and 2-propanol is 34.9 and $0.7 \%$, respectively, at $210{ }^{\circ} \mathrm{C}$ and an $\mathrm{H}_{2}$ pressure of $41 \mathrm{~atm}$. Ryneveld et al. have studied supported $\mathrm{Ru}, \mathrm{Pd}$, and Pt catalysts for glycerol hydrogenolysis [171]. Pd/C shows the best catalytic performance for 1-propanol formation via 1,2-PDO as an intermediate: the selectivity to 1 -propanol is $72.6 \%$ at $20.3 \%$ conversion at $230{ }^{\circ} \mathrm{C}$. Although 1-propanol is readily dehydrated into propylene at a high temperature of $230{ }^{\circ} \mathrm{C}$, there is no description about the analysis of gaseous products. Tomishige's group has investigated $\mathrm{Rh}-\mathrm{ReO}_{\mathrm{x}} / \mathrm{SiO}_{2}$ catalyst, which is efficient for propanols formation from glycerol [168]. The selectivity to 1,2-PDO and 1,3-PDO are 30 and 15\%, respectively, at $120{ }^{\circ} \mathrm{C}$ and an $\mathrm{H}_{2}$ pressure of 8 atm at a reaction time of $5 \mathrm{~h}$, and they decrease with increasing the reaction time. 1,2-PDO and 1,3-PDO are completely converted into propanols at a reaction time of $24 \mathrm{~h}$, and 76\% yield of 1-propanol and 15\% yield of 2-propanol are achieved. In their recent study, $\mathrm{Ru}$ promoted $\mathrm{Ir}-\mathrm{ReO}_{\mathrm{X}} / \mathrm{SiO}_{2}$ catalyst also shows activity for propanols formation, and the maximum total yield of propanols is $86 \%$ at $120{ }^{\circ} \mathrm{C}$ and an $\mathrm{H}_{2}$ pressure of 80 atm [169]. It is supposed that $\mathrm{Ru}$ can dissociate an $\mathrm{H}_{2}$ molecule into two $\mathrm{H}$ species such as two $\mathrm{H}$ radicals, and they can spill over onto Ir-ReOx species as shown in Fig 8. The high activity of $\mathrm{Ru}-\mathrm{Ir}-\mathrm{ReO}_{\mathrm{x}} / \mathrm{SiO}_{2}$ was proposed to attribute to the increase of the active $\mathrm{H}$ species on Ir-ReOx species. Yu et al. have reported a high 1-propanol yield of $94 \%$ over $\mathrm{Ir} / \mathrm{ZrO}_{2}$ [172]. Ir shows the highest activity to produce 1-propanol among other metals such as $\mathrm{Pt}, \mathrm{Pd}, \mathrm{Rh}$, and $\mathrm{Ru}$, where $\mathrm{ZrO}_{2}$ support shows better performance than other supports such as $\mathrm{Al}_{2} \mathrm{O}_{3}, \mathrm{TiO}_{2}, \mathrm{C}$, and $\mathrm{SiO}_{2}$. The yield of 1-propanol is significantly affected by the reaction temperature, and is maximized at $250{ }^{\circ} \mathrm{C}$ over $\mathrm{Ir} / \mathrm{ZrO}_{2}$. Over 
the $\mathrm{ZrO}_{2}$ support, the selectivity to further hydrogenolysis products such as propylene is lower than $5 \%$ even at $250{ }^{\circ} \mathrm{C}$.

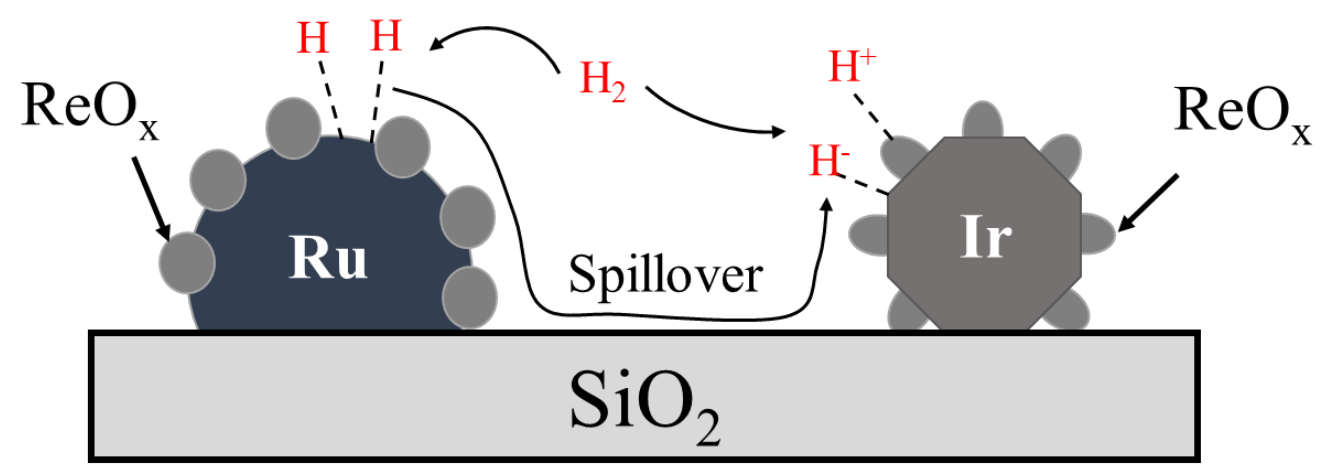

Figure 8 Proposed catalyst and reaction model in Ref. [169].

Table 10 Hydrogenolysis of glycerol into propanols using a batch-type reactor.

\begin{tabular}{cccccccccc}
\hline Catalyst & Temp. & $\mathrm{H}_{2}$ & Solvent & Glycerol/ & Time & Conversion & Selectivity to & Selectivity to & Ref. \\
& & Catalyst & & of glycerol & 1-propanol & 2-propanol & \\
& $\left({ }^{\circ} \mathrm{C}\right)$ & $(\mathrm{atm})$ & & $(\mathrm{g} / \mathrm{g})$ & $(\mathrm{h})$ & $(\%)$ & $(\%)$ & $(\%)$ & \\
\hline $\mathrm{Rh}^{2}-\mathrm{ReO}_{\mathrm{x}} / \mathrm{SiO}_{2}$ & 120 & 80 & neat & 26.7 & 24 & 100 & 76 & 15 & 168 \\
$\mathrm{Ru}-\mathrm{Ir}-\mathrm{ReO}_{\mathrm{x}} / \mathrm{SiO}_{2}$ & 120 & 80 & $\mathrm{H}_{2} \mathrm{O}$ & 26.7 & 19 & 100 & 71 & 15 & 169 \\
$\mathrm{Copper}$ chromite & 210 & 41 & $\mathrm{H}_{2} \mathrm{O}$ & 20 & 10 & 49.2 & 34.9 & 0.7 & 170 \\
$\mathrm{Pd} / \mathrm{C}$ & 230 & 80 & $\mathrm{H}_{2} \mathrm{O}$ & 20 & 24 & 20.3 & 72.6 & 0.0 & 171 \\
$\mathrm{Ir} / \mathrm{ZrO}_{2}$ & 250 & 50 & $\mathrm{H}_{2} \mathrm{O}$ & Unclear & 4 & 100 & 94 & - & 172 \\
\hline
\end{tabular}

Table 11 summarizes the vapor-phase glycerol hydrogenolysis into propanols. $\mathrm{SiO}_{2}$-supported $\mathrm{Ni}$ catalyst gives $42.8 \%$ yield of 1-propanol at a high temperature of $320{ }^{\circ} \mathrm{C}$ and an $\mathrm{H}_{2}$ pressure of $60 \mathrm{~atm}$, whereas even higher selectivity is difficult to be obtained because of the competitive formation of cracking products, such as methanol and ethanol [173,174]. $\mathrm{Pt}-\mathrm{H}_{4} \mathrm{SiW}_{12} \mathrm{O}_{40} / \mathrm{ZrO}_{2}$ is reported to be very efficient for the formation of propanols from glycerol: the total yield of propanols of $91 \%$ is achieved at $200{ }^{\circ} \mathrm{C}$ and an $\mathrm{H}_{2}$ pressure of 50 atm [175]. Crude glycerol can be also used as the reactant in the catalyst system: $c a$. $90 \%$ yield of propanols is 
achieved at the same reaction conditions. The catalyst is stable and catalytic deactivation is not observed during $160 \mathrm{~h}$ at a relatively low WHSV of $0.05 \mathrm{~h}^{-1}$. Lin et al. performed glycerol hydrogenolysis over double-layered catalysts, in which $\mathrm{H}-\beta$ zeolite is loaded at the upper layer to catalyze glycerol dehydration into acrolein and $\mathrm{Ni} / \mathrm{Al}_{2} \mathrm{O}_{3}$ is loaded at the bottom layer to hydrogenate acrolein into 1-propanol [176]: a 69\% yield of 1-proapnol is obtained at $220{ }^{\circ} \mathrm{C}$ and an $\mathrm{H}_{2}$ pressure of $20 \mathrm{~atm}$ at an initial TOS of $0.5 \mathrm{~h}$, whereas the upper-layer catalyst is deactivated rapidly because of the coke formation caused by acrolein.

Glycerol hydrogenolysis into propanols requires an acidity in the catalyst, which must be active for dehydration of 1,2-PDO or 1,3-PDO but inactive for further dehydration of propanols. Catalysts, such as $\mathrm{Ir} / \mathrm{ZrO}_{2}$ [172] and $\mathrm{Pt}-\mathrm{H}_{4} \mathrm{SiW}_{12} \mathrm{O}_{40} / \mathrm{ZrO}_{2}$ [175], which give higher than $90 \%$ yields of propanols, possibly have the suitable acidity. Two-step production of 1-propanol from glycerol via acrolein has no problem in the further dehydration of propanols [176]. However, inhibition of catalyst deactivation is a difficult problem in the process.

Table 11 Vapor-phase glycerol hydrogenolysis into propanols

\begin{tabular}{|c|c|c|c|c|c|c|c|c|}
\hline \multirow[t]{3}{*}{ Catalyst } & Temp. & Pressure & TOS & WHSV & Conversion & Selectivity to & Selectivity to & Ref. \\
\hline & & & & & of glycerol & 1-propanol & 2-propanol & \\
\hline & $\left({ }^{\circ} \mathrm{C}\right)$ & (atm) & (h) & $\left(h^{-1}\right)$ & $(\%)$ & $(\%)$ & $(\%)$ & \\
\hline $\mathrm{Ni} / \mathrm{SiO}_{2}$ & 320 & 60 & unclear & 2.2 & 99.9 & 42.8 & - & 173 \\
\hline $\mathrm{Pt}-\mathrm{H}_{4} \mathrm{SiW}_{12} \mathrm{O}_{40} / \mathrm{ZrO}_{2}$ & 200 & 50 & 160 & 0.05 & 99.7 & 80.0 & 10.9 & 175 \\
\hline Zeolite $+\mathrm{Ni} / \mathrm{Al}_{2} \mathrm{O}_{3}$ & 220 & 20 & 0.5 & 1.9 & 100 & 69 & - & 176 \\
\hline
\end{tabular}

\subsection{Propylene}

Propylene can be produced from glycerol multi-step hydrogenolysis via 1-propanol dehydration. Since propylene has lower market value than other products, such as propanediols and propanols, high level of propylene selectivity is required in such a process. Table 12 summarizes vapor-phase glycerol hydrogenolysis into propylene. Yu et al. firstly reported the selective production of propylene from glycerol over double-layered catalysts, in which $\mathrm{Ir} / \mathrm{ZrO}_{2}$ is loaded at 
the upper layer and HZSM-5 is loaded at the lower layer [172]. $\mathrm{Ir} / \mathrm{ZrO}_{2}$ is introduced to be an efficient catalyst for 1-propanol formation from glycerol in Section 4.2, and HZSM-5 is used for the further conversion of 1-propanol into propylene. High $\mathrm{H}_{2}$ pressures are required to promote glycerol conversion in the catalyst system, while high $\mathrm{H}_{2}$ pressures decrease the selectivity to propylene which is hydrogenated into propane. As a consequence, the maximum yield of propylene is achieved at $85 \%$ under a moderate $\mathrm{H}_{2}$ pressure of $10 \mathrm{~atm}$.

Table 12 Vapor-phase glycerol hydrogenolysis into propylene

\begin{tabular}{cccccccc}
\hline Catalyst & Temp. & Pressure & TOS & WHSV & $\begin{array}{c}\text { Conversion of } \\
\text { glycerol }\end{array}$ & $\begin{array}{c}\text { Selectivity to } \\
\text { propylene }\end{array}$ & Ref. \\
& & & & & & & \\
& $\left({ }^{\circ} \mathrm{C}\right)$ & $(\mathrm{atm})$ & $(\mathrm{h})$ & $\left(\mathrm{h}^{-1}\right)$ & $1 \%)$ & $(\%)$ & 172 \\
\hline $\mathrm{Ir} / \mathrm{ZrO}_{2}+\mathrm{HZSM}-5$ & 250 & 10 & 2 & 1 & 100 & 85 & 177 \\
$\mathrm{WO}_{3}-\mathrm{Cu} / \mathrm{Al}_{2} \mathrm{O}_{3}$ (upper) & 250 & 1 & $2-5^{\mathrm{a}}$ & 0.2 & 100 & 84.8 & \\
$+\mathrm{SiO}_{2}-\mathrm{Al}_{2} \mathrm{O}_{3}$ (bottom) & & & & & & & \\
\hline
\end{tabular}

${ }^{\mathrm{a}}$ Averaged value in $2-5 \mathrm{~h}$.

Sato's group recently reported the efficient glycerol conversion into propylene at an atmospheric $\mathrm{H}_{2}$ pressure [177]. $\mathrm{WO}_{3}$-modified $\mathrm{Cu} / \mathrm{Al}_{2} \mathrm{O}_{3}$ catalyst was investigated and it gave 38.2 and $47.4 \%$ selectivity to 1-propanol and propylene, respectively, with a complete conversion of glycerol at $250{ }^{\circ} \mathrm{C}$. Although $\mathrm{WO}_{3}-\mathrm{Cu} / \mathrm{Al}_{2} \mathrm{O}_{3}$ is efficient for glycerol hydrogenolysis into 1-propanol, the ability to further convert 1-propanol into propylene as an acid catalyst is low. Thus, the reaction using double-layered catalysts, in which $\mathrm{WO}_{3}-\mathrm{Cu} / \mathrm{Al}_{2} \mathrm{O}_{3}$ is loaded at the upper layer and $\mathrm{SiO}_{2}-\mathrm{Al}_{2} \mathrm{O}_{3}$ is loaded at the bottom layer to convert 1-propanol into propylene completely, is performed: an $84.8 \%$ yield of propylene is achieved over the double-layered catalysts at $250{ }^{\circ} \mathrm{C}$ at an ambient $\mathrm{H}_{2}$ pressure. In addition, in such a multi-step dehydration-hydrogenation process, although acetol and propanal can be completely hydrogenated to 1,2-propanediol and 1-propanol, respectively, no hydrogenation of propylene proceeds and the selectivity to propane is at most $1 \%$. It is supposed that the carbonyl group in acetol and propanal is readily absorbed on the $\mathrm{Cu}$ surface comparing with the 
double bond in propylene, which results to the selective production of propylene. Zacharopoulou et al. reported a liquid-phase glycerol hydrogenolysis into propylene using Fe-Mo/C catalyst [178]. The maximum conversion and propylene selectivity are 88 and 76\%, respectively, which are achieved at $300{ }^{\circ} \mathrm{C}$ and an $\mathrm{H}_{2}$ pressure of $80 \mathrm{~atm}$ at a reaction time of $6 \mathrm{~h}$. It is found that high reaction temperatures and $\mathrm{H}_{2}$ pressures promote glycerol conversion toward propylene, and suppress the formation of by-products such as acetol, propanols, 1,2-PDO, and 1,3-PDO. In the reaction route of propylene formation over $\mathrm{Fe}-\mathrm{Mo} / \mathrm{C}$, it is interesting that allyl alcohol is proved to be an intermediate of propylene, which is different from propanal reported in the vapor-phase reaction [177].

\section{Concluding remarks and prospects}

Glycerol is the smallest polyol readily available from biomass, and it is now produced as a large amount of waste in the biodiesel production process. Glycerol can be converted to various useful chemicals, and glycerol hydrogenolysis into C3 useful chemicals, such as 1,2-PDO, 1,3-PDO, allyl alcohol, propanols, and propylene, is particularly summarized and discussed in this review.

Glycerol conversion into 1,2-PDO is mostly investigated among the glycerol hydrogenolysis processes, and most of the studies are performed in batch-type reactors at a high $\mathrm{H}_{2}$ pressure. Liquid-phase glycerol hydrogenolysis into 1,2-PDO can be catalyzed over various precious metal catalysts, whereas only $\mathrm{Cu}$ shows high selectivity toward 1,2-PDO in a vapor-phase reaction because most of the precious metals enhance the formation of the $\mathrm{C}-\mathrm{C}$ cleavage products. $\mathrm{Cu}$ also shows the best catalyst performance in liquid-phase reactions. In the vapor phase, on the other hand, $\mathrm{Cu}$ metal species work as catalysts both for the dehydration of glycerol and for the hydrogenation of acetol. It is summarized that vapor-phase processes over $\mathrm{Cu}$ catalysts are more preferable than liquid-phase reactions in the selective formation of 1,2-PDO in glycerol hydrogenolysis. 1,2-PDO is produced with the highest yield of $98.3 \%$ in the vapor-phase reaction over $\mathrm{Ag}-\mathrm{Cu} / \mathrm{Al}_{2} \mathrm{O}_{3}$ catalyst under ambient $\mathrm{H}_{2}$ pressure [77]. Because the particle size of metal significantly affects the catalytic activity, further developments of the catalyst preparation techniques for controlling the catalyst structure would be highly required. On the other hand, theoretical studies such as quantum-chemical calculations have rarely been reported to support 
speculative reaction mechanisms whereas some possible reaction mechanisms have been proposed. In further studies, quantum-chemical calculations are essential to understand the exact surface reaction mechanism.

1,3-PDO is the most attractive chemical which can be derived from glycerol. Recently, research interest has been alerted from 1,2-PDO to 1,3-PDO while 1,3-PDO is much more difficult to be selectively produced. Because 3-hydroxypropanal, the intermediate of 1,3-PDO, is ready to be dehydrated into acrolein under acidic conditions before the hydrogenation of 3-hydroxypropanal proceeds to form 1,3-PDO, successful glycerol hydrogenolysis into 1,3-PDO requires a catalyst system with the ability to promote the coupled dehydration-hydrogenation reactions as well as to minimize the side reactions. The stability of 1,3-PDO under catalytic conditions is another problem limiting the selective production of 1,3-PDO from glycerol. The maximum yield of 1,3-PDO achieved from glycerol is $66 \%$ over $\mathrm{Pt}-\mathrm{WO}_{\mathrm{x}} / \mathrm{AlOOH}$ catalyst [140], and how to increase the 1,3-PDO selectivity is a key of challenge in future studies.

Allyl alcohol can be generated from glycerol via 1,3-PDO dehydration and acrolein hydrogenation, whereas it is difficult to be produced selectively because it is easy to be further hydrogenated into 1-propanol under $\mathrm{H}_{2}$ pressured conditions. As a consequence, the studies aimed to produce allyl alcohol from glycerol are performed in the absence of $\mathrm{H}_{2}$, in which either monoalcohol or acid is used as the $\mathrm{H}$ donor instead of $\mathrm{H}_{2}$. Allyl alcohol can be achieved from glycerol at $c a .90 \%$ yield in the presence of methyltrioxorhenium catalyst [157] and formic acid [155] in a liquid phase.

Propanols and propylene can also be selectively produced from glycerol via multi dehydration-hydrogenation steps. The formation of propanols from glycerol requires an acid catalyst component, which is active for the dehydration of glycerol, 1,2-PDO, and 1,3-PDO but it must be inactive for the further dehydration of propanols. Higher than $90 \%$ yields of propanols have been achieved in several reports $[168,169,172,175]$. Propylene yield of $84.8 \%$ is achieved in vapor-phase glycerol hydrogenolysis over $\mathrm{WO}_{3}$-modified $\mathrm{Cu} / \mathrm{Al}_{2} \mathrm{O}_{3}$ and $\mathrm{SiO}_{2}-\mathrm{Al}_{2} \mathrm{O}_{3}$ double-layered catalysts at an ambient $\mathrm{H}_{2}$ pressure [177].

The above-mentioned C3 chemicals are all bulk chemicals, which are commercially 
produced from fossil resources at present. Therefore, in glycerol hydrogenolysis processes, the atomic efficiency and the productivity are very important. From this point of view, a vapor-phase continuous system using flow type reactors is preferable comparing with a batch system. Recent progress in the technologies of catalytic transformation of glycerol makes it possible to produce these chemicals from renewable resources. However, there is still an opportunity for the development of more efficient catalysts without containing precious metals. In the research of glycerol hydrogenolysis, although noble metals have been widely used as the hydrogenation catalysts, it would be unrealistic to use the noble metal-containing catalysts in industrial processes, particularly because indefinite reusability of these catalysts is not possible. Therefore, replacement of noble metals by abundant base metals is necessary for the practical usage. In the early 2016, it is a hard time for biomass-based industrial processes during the drops in the price of fossil resources. However, it is probably just a question of time until we see more processes on glycerol conversion technology in the future.

\section{Acknowledgements}

This research was partly supported by JST, Strategic International Collaborative Research Program, SICORP.

\section{References}

[1] J. E. Rekoske, M. A. Barteau, Ind. Eng. Chem. Res. 50 (2011) 41-51.

[2] A. Corma, S. Iborra, A. Velty, Chem. Rev. 107 (2007) 2411-2502.

[3] C. A. G. Quispe, C. J. R. Coronado, J. A. Carvalho Jr., Renew. Sust. Energ. Rev. 27 (2013) 475-493.

[4] M. Parikka, Biomass Bioenerg. 27 (2004) 613-620.

[5] J. ten Dam, U. Hanefeld, ChemSusChem 4 (2011) 1017-1034.

[6] Y. Nakagawa, K. Tomishige, Catal. Sci. Technol. 1 (2011) 179-190.

[7] B. Katryniok, S. Paul, F. Dumeignil, ACS Catal. 3 (2013) 1819-1834.

[8] F. Bauer, C. Hulteberg, Biofuels Bioprod. Bioref. 7 (2013) 43-51.

[9] C. S. Callam, S. J. Singer, T. L. Lowary, C. M. Hadad, J. Am. Chem. Soc. 123 (2001) 11743-11754. 
[10] B. Katryniok, S. Paul, V. Belliere-Baca, P. Rey, F. Dumeignil, Green Chem. 12 (2010) 2079-2098.

[11] C.H. Zhou, J.N. Beltramini, Y. X. Fan, G. Q. Lu, Chem. Soc. Rev. 37 (2008) 527-549.

[12] A. Behr, J. Eilting, K. Irawadi, J. Leschinski, F. Lindner, Green Chem. 10 (2008) 13-30.

[13] J. Barrault, F. Jérome, Eur. J. Lipid Sci. Technol. 110 (2008) 825-830.

[14] M. Pagliaro, R. Ciriminna, H. Kimura, M. Rossi, C. D. Pina, Angew. Chem. Int. Ed. 46 (2007) 4434-4440.

[15] M. Pagliaro, M. Rossi, The Future of Glycerol: New Uses of a Versatile Raw Material, Royal Society of Chemistry, UK, 2008.

[16] C. H. Zhou, H. Zhao, D. S. Tong, L. M. Wu, W. H. Yu, Catal. Rev. 55 (2013) 369-453.

[17] S. Bagheri, N. M. Julkapli, W. A. Yehye, Renew. Sust. Energ. Rev. 41 (2015) 113-127.

[18] B. Katryniok, S. Paul, M. Capron, F. Dumeignil, ChemSusChem 2 (2009) 719-730.

[19] A. Martin, U. Armbruster, H. Atia, Eur. J. Lipid Sci. Technol. 114 (2012) 10-23.

[20] L. Liu, X.P. Ye, J. J. Bozell, ChemSusChem 5 (2012) 1162-1180.

[21] A. Talebian-Kiakalaieh, N. A. S. Amin, H. Hezaveh, Renew. Sust. Energ. Rev. 40 (2014) 28-59.

[22] J. Deleplanque, J.-L. Dubois, J.-F. Devaux, W. Ueda, Catal. Today 157 (2010) 351-358.

[23] K. Omata, K. Matsumoto, T. Murayama, W. Ueda, Chem. Lett. 43 (2014) 435-437.

[24] T. Katou, D. Vitry, W. Ueda, Catal. Today 91-92 (2004) 237-240.

[25] W. Ueda, D. Vitry, T. Katou, Catal. Today 96 (2004) 205-209.

[26] W. Ueda, D. Vitry, T. Katou, Catal. Today 99 (2005) 43-49.

[27] M. D. Soriano, P. Concepción, J.M.L Nieto, F. Cavani, S. Guidetti, C. Trevisanut, Green Chem., 13 (2011) $2954-2962$

[28] A. Chieregato, F. Basile, P. Concepción, S. Guidetti, G. Liosi, M.D. Soriano, C. Trevisanut, F. Cavani, J.M.L. Nieto, Catal. Today 197 (2012) 58-65.

[29] A. Chieregato, M. D. Soriano, F. Basile, G. Liosi, S. Zamora, P. Concepción, F. Cavani, J. M. L. Nieto, Appl. Catal. B: Environ. 150-151 (2014) 37-46.

[30] A. Chieregato, M. D. Soriano, E. García-González, G. Puglia, F. Basile, P. Concepción, C. Bandinelli, J. M. L. Nieto, F. Cavani, ChemSusChem 8 (2015) 398-406.

[31] L. G. Possato, W.H. Cassinelli, T. Garetto, S. H. Pulcinelli, C. V. Santilli, L. Martinsa, Appl. Catal. A: Gen. 492 (2015) 243-251. 
[32] C. F. M. Pestana, A. C. O. Guerra, G. B. Ferreira, C. C. Turcia, C. J. A. Mota, J. Braz. Chem. Soc. 24 (2013) 100-105.

[33] L. Liu, B. Wang, Y. Du, Z. Zhong, A. Borgna, Appl. Catal. B: Environ. 174-175 (2015) 1-12.

[34] A. Witsuthammakul, T. Sooknoi, Appl. Catal. A: Gen. 413-414 (2012) 109-116.

[35] R. Liu, T. Wang, D. Cai, Y. Jin, Ind. Eng. Chem. Res. 53 (2014) 8667-8674.

[36] S. Thanasilp, J. W. Schwank, V. Meeyoo, S. Pengpanich, M. Hunsom, J. Mol. Catal. A: Chem. 380 (2013) 49-56.

[37] B. Sarkar, C. Pendem, L.N.S. Konathala, R. Tiwari, T. Sasaki, R. Bal, Chem. Commun. 50 (2014) 9707-9710.

[38] B. Katryniok, H. Kimura, E. Skrzyńska, J. Girardon, P. Fongarland, M. Capron, R. Ducoulombier, N. Mimura, S. Paul, F. Dumeignil, Green Chem. 13 (2011) 1960-1979.

[39] A. Villa, N. Dimitratos, C. E. Chan-Thaw, C. Hammond, L. Prati, G. J. Hutchings, Acc. Chem. Res. 48 (2015) 1403-1412.

[40] Y. Shen, S. Zhang, H. Li, Y. Ren, H. Liu, Chem. Eur. J. 16 (2010) 7368-7371.

[41] D. Roy, B. Subramaniam, R. V. Chaudhari, ACS Catal. 1 (2011) 548-551.

[42] F. Auneau, L.S. Arani, M. Besson, L. Djakovitch, C. Michel, F. Delbecq, P. Sautet, C. Pinel, Top Catal. 55 (2012) 474-479.

[43] P. Lakshmanan, P.P. Upare, N. Le, Y. K. Hwang, D. W. Hwang, U. Lee, H.R. Kim, J. Chang, Appl. Catal. A: Gen. 468 (2013) 260-268.

[44] J. Xu, H. Zhang, Y. Zhao, B. Yu, S. Chen, Y. Li, L. Hao, Z. Liu, Green Chem. 15 (2013) 1520-1525.

[45] R. K. P. Purushothaman, J. van Haveren, A. Mayoral, I. Melián-Cabrera, H. J. Heeres, Top Catal. 57 (2014) $1445-1453$

[46] H.J. Cho, C. Chang, W. Fan, Green Chem. 16 (2014) 3428-3433.

[47] Y. Zhang, Z. Shen, X. Zhou, M. Zhang, F. Jin, Green Chem. 14 (2012) 3285-3288.

[48] H. Kishida, F. Jin, Z. Zhou, T. Moriya, H. Enomoto, Chem. Lett. 34 (2005) 1560-1561.

[49] Z. Shen, F. Jin, Y. Zhang, B. Wu, A. Kishita, K. Tohji, H. Kishida, Ind. Eng. Chem. Res. 48 (2009) 8920-8925.

[50] C. A. Ramírez-López, J. R. Ochoa-Gómez, M. Fernández-Santos, O. Gómez-Jiménez-Aberasturi, A. Alonso-Vicario, J. Torrecilla-Soria, Ind. Eng. Chem. Res. 49 (2010) 6270-6278.

[51] T. Shimanouchi, S. Ueno, K. Shidahara, Y. Kimura, Chem. Lett. 43 (2014) 535-537.

[52] L. Chen, S. Ren, X.P. Ye, React. Kinet. Mech. Cat. 114 (2015) 93-108.

[53] R. K. P. Purushothaman, J. van Haveren, D. S. van Es, I. Melián-Cabrera, J. D. Meeldijk, H. J. Heeres, Appl. Catal. 
B: Environ. 147 (2014) 92-100.

[54] Y. Li, M. Nielsen, B. Li, P. H. Dixneuf, H. Junge, M. Beller, Green Chem. 17 (2015) 193-198.

[55] T. van Haasterecht, T. W. van Deelen, K. P. de Jong, J. H. Bitter, Catal. Sci. Technol. 4 (2014) 2353-2366.

[56] D. M. Alonso, S. G. Wettstein, J. A. Dumesic, Chem. Soc. Rev. 41 (2012) 8075-8098.

[57] A. M. Ruppert, K. Weinberg, R. Palkovits, Angew. Chem. Int. Ed. 51 (2012) 2564-2601.

[58] J. Ma, W. Yu, M. Wang, X. Jia, F. Lu, J. Xu, Chin. J. Catal. 34 (2013) 492-507.

[59] R. V. Chaudhari, A. Torres, X. Jin, B. Subramaniam, Ind. Eng. Chem. Res. 52 (2013) 15226-15243.

[60] A. Martin, U. Armbruster, I. Gandarias, P. L. Arias, Eur. J. Lipid Sci. Technol. 115 (2013) 9-27.

[61] K. Tomishige, Y. Nakagawa, M. Tamura, Top Curr. Chem. 353 (2014) 127-162.

[62] M. Besson, P. Gallezot, C. Pinel, Chem. Rev. 114 (2014) 1827-1870.

[63] J. Feng, B. Xu, Prog. React. Kinet. Mech. 39 (2014) 1-15.

[64] C. S. Lee, M. K. Aroua, W. M. A. W. Daud, P. Cognet, Y. Pérès-Lucchese, P-L. Fabre, O. Reynes, L. Latapie, Renew. Sust. Energ. Rev. 42 (2015) 963-972.

[65] Y. Wang, J. Zhou, X. Guo, RSC Adv. 5 (2015) 74611-74628.

[66] T. Miyazawa, Y. Kusunoki, K. Kunimori, K. Tomishige, J. Catal. 240 (2006) 213-221.

[67] E. P. Maris, R. J. Davis, J. Catal. 249 (2007) 328-337.

[68] T. Miyazawa, S. Koso, K. Kunimori, K. Tomishige, Appl. Catal. A: Gen. 318 (2007) 244-251.

[69] J. Chaminand, L. Djakovitch, P. Gallezot, P. Marion, C. Pinel, C. Rosier, Green Chem. 6 (2004) 359-361.

[70] C. Montassier, J. C. Menezo, L. C. Hoang, C. Renaud, J. Barbier, J. Mol. Catal. A: Chem. 70 (1991) 99-110.

[71] J. Feng, J. Wang, Y. Zhou, H. Fu, H. Chen, X. Li, Chem. Lett. 36 (2007) 1274-1275.

[72] A. Alhanash, E. F. Kozhevnikova, I. V. Kozhevnikov, Appl. Catal. A: Gen. 378 (2010) 11-18.

[73] Y. Amada, Y. Shinmi, S. Koso, T. Kubota, Y. Nakagawa, K. Tomishige, Appl. Catal. B: Environ. 105 (2011) 117-127.

[74] M. Akiyama, S. Sato, R. Takahashi, K. Inui, M. Yokota, Appl. Catal. A: Gen. 371 (2009) 60-66.

[75] S. Sato, M. Akiyama, K. Inui, M. Yokota, Chem. Lett. 38 (2009) 560-561.

[76] S. Sato, D. Sakai, F. Sato, Y. Yamada, Chem. Lett. 41 (2012) 965-966.

[77] D. Sun, Y. Yamada, S. Sato, Appl. Catal. A: Gen. 475 (2014) 63-68.

[78] S. Sato, M. Akiyama, R. Takahashi, T. Hara, K. Inui, M. Yokota, Appl. Catal. A: Gen. 347 (2008) 186-191.

[79] S. R. Schmidt, S. K. Tanielyan, N. Marin, G. Alvez, R. L. Augustine, Top Catal. 53 (2010) 1214-1216. 
[80] S. K. Tanielyan, N. Marin, G. Alvez, R. Bhagat, B. Miryala, R. L. Augustine, S. R. Schmidt, Org. Process Res. Dev. 18 (2014) 1419-1426.

[81] I. Gandarias, P. L. Arias, J. Requies, M. B. Güemez, J. L. G. Fierro, Appl. Catal. B: Environ. 97 (2010) 248-256.

[82] I. Furikado, T. Miyazawa, S. Koso, A. Shimao, K. Kunimori, K. Tomishige, Green Chem. 9 (2007) 582-588.

[83] A. Shimao, S. Koso, N. Ueda, Y. Shinmi, I. Furikado, K. Tomishige, Chem. Lett. 38 (2009) 540-541.

[84] J. Feng,W. Xiong, B. Xu, W. Jiang, J. Wang, H. Chen, Catal. Commun. 46 (2014) 98-102.

[85] F. Auneau, S. Noël, G. Aubert, M. Besson, L. Djakovitch, C. Pinel, Catal. Commun. 16 (2011) 144-149.

[86] N. Hamzah, N. M. Nordin, A. H. A. Nadzri, Y. A. Nik, M. B. Kassim, M. A. Yarmo, Appl. Catal. A: Gen. 419-420 (2012) 133-141.

[87] S. Lee, D. J. Moon, Catal. Today 174 (2011) 10-16.

[88] J. Zhou, J. Zhang, X. Guo, J. Mao, S. Zhang, Green Chem. 14 (2012) 156-163.

[89] D. Sun, Y. Yamada, S. Sato, Appl. Catal. A: Gen. 487 (2014) 234-241.

[90] M. A. Dasari, P. Kiatsimkul, W. R. Sutterlin, G.J. Suppes, Appl. Catal. A: Gen. 281 (2005) 225-231.

[91] D. Durán-Martín, M. Ojeda, M. López Granados, J. L. G. Fierro, R. Mariscal, Catal. Today 210 (2013) 98-105.

[92] M. Balaraju, V. Rekha, P. S. S. Prasad, R. B. N. Prasad, N. Lingaiah, Catal. Lett. 126 (2008) 119-124.

[93] Z. Wu, Y. Mao, M. Song, X. Yin, M. Zhang, Catal. Commun. 32 (2013) 52-57.

[94] P. Hirunsit, C. Luadthong, K. Faungnawakij, RSC Adv. 5 (2015) 11188-11197.

[95] E. S. Vasiliadou, T. M. Eggenhuisen, P. Munnik, P. E. de Jongh, K. P. de Jong, A. A. Lemonidou, Appl. Catal. B: Environ. 145 (2014) 108-119.

[96] Z. Yuan, J. Wang, L. Wang, W. Xie, P. Chen, Z. Hou, X. Zheng, Bioresour. Technol. 101 (2010) 7088-7092.

[97] Z. Yuan, L. Wang, J. Wang, S. Xia, P. Chen, Z. Hou, X. Zheng, Appl. Catal. B: Environ. 101 (2011) 431-440.

[98] X. Guo, Y. Li, W. Song, W. Shen, Catal. Lett. 141 (2011) 1458-1463.

[99] A. Perosa, P. Tundo, Ind. Eng. Chem. Res. 44 (2005) 8535-8537.

[100] Y. Li, H. Liu, L. Ma, D. He, RSC Adv. 4 (2014) 5503-5512.

[101] J. B. Salazar, D. D. Falcone, H. N. Pham, A. K. Datye, F. B. Passos, R. J. Davis, Appl. Catal. A: Gen. 482 (2014) $137-144$.

[102] T. Jiang, Y. Zhou, S. Liang, H. Liu, B. Han, Green Chem. 11 (2009) 1000-1006.

[103] J. Zhou, L. Guo, X. Guo, J. Mao, S. Zhang, Green Chem. 12 (2010) 1835-1843. 
[104] S. Xia, Z. Yuan, L. Wang, P. Chen, Z. Hou, Appl. Catal. A: Gen. 403 (2011) 173-182.

[105] D. Stošić, S. Bennici, S. Sirotin, P. Stelmachowski, J. Couturier, J. Dubois, A. Travert, A. Auroux, Catal. Today 226 (2014) 167-175.

[106] R. B. Mane, A. Yamaguchi, A. Malawadkar, M. Shirai, C.V. Rode, RSC Adv. 3 (2013) 16499-16508.

[107] E. D’Hondt, S. V. de Vyver, B. F. Sels, P. A. Jacobs, Chem. Commun. (2008) 6011-6012.

[108] M. L. Barbelli, G. F. Santori, N. N. Nichio, Bioresource Technol. 111 (2012) 500-503.

[109] M. G. Musolino, L. A. Scarpino, F. Mauriello, R. Pietropaolo, Green Chem. 11 (2009) 1511-1513.

[110] S. Xia, L. Zheng, L. Wang, P. Chen, Z. Hou, RSC Adv. 3 (2013) 16569-16576.

[111] I. Gandarias, J. Requies, P. L. Arias, U. Armbruster, A. Martin, J. Catal. 290 (2012) 79-89.

[112] I. Gandarias, P. L. Arias, S. G. Fernández, J. Requies, M. E. Doukkali, M.B. Güemez, Catal. Today 195 (2012) 22-31.

[113] I. Gandarias, S. G. Fernandez, M. E. Doukkali, J. Requies, P. L. Arias, Top Catal. 56 (2013) 995-1007.

[114] F. Mauriello, H. Ariga, M. G. Musolino, R. Pietropaolo, S. Takakusagi, K. Asakura, Appl. Catal. B: Environ. $166-167$ (2015) 121-131.

[115] E. S. Vasiliadou, V.-L. Yfanti, A. A. Lemonidou, Appl. Catal. B: Environ. 163 (2015) 258-266.

[116] C. Montassier, D. Giraud, J. barbier, J. Stud. Surf. Sci. Catal. 41 (1988) 165-170.

[117] C. W. Chiu, A. Tekeei, W. R. Sutterlin, J. M. Ronco, G. J. Suppes, AIChE J. 54 (2008) 2456-2463.

[118] C. W. Chiu, A. Tekeei, J. M. Ronco, M. L. Banks, G. J. Suppes, Ind. Eng. Chem. Res. 47 (2008) 6878-6884.

[119] A. Bienholz, H. Hofmann, P. Claus, Appl. Catal. A: Gen. 391 (2011) 153-157.

[120] S. Zhu, X. Gao, Y. Zhu, Y. Zhu, H. Zheng, Y. Li, J. Catal. 303 (2013) 70-79.

[121] S. Zhu, X. Gao, Y. Zhu, W. Fan, J. Wang, Y. Li, Catal. Sci. Technol. 5 (2015) 1169-1180.

[122] S. Zhu, X. Gao, Y. Zhua, Y. Li, Green Chem. 18 (2016) 782-791.

[123] S. Sato, R. Takahashi, T. Sodesawa, H. Fukuda, T. Sekine, E. Tsukuda, Catal. Commun. 6 (2005) 607-610.

[124] L. Huang, Y. Zhu, H. Zheng, Y. Li, Z. Zeng, J. Chem. Technol. Biotechnol. 83 (2008) 1670-1675.

[125] S. Panyad, S. Jongpatiwut, T. Sreethawong, T. Rirksomboon, S. Osuwan, Catal. Today 174 (2011) 59-64.

[126] T. Li, C. Fu, J. Qi, J. Pan, S. Chen, J. Lin, Reac. Kinet. Mech. Cat. 109 (2013) 117-131.

[127] M. Harisekhar, V. P. Kumar, S. S. Priya, K. V. R. Chary, Chem. Technol. Biotechnol. 90 (2015) 1906-1917.

[128] G. D. Yadav, P. A. Chandan, D. P. Tekale, Ind. Eng. Chem. Res. 51 (2012) 1549-1562. 
[129] P. K. Vanama, A. Kumar, S. R. Ginjupalli, V. R. C. Komandur, Catal. Today 250 (2015) 226-238.

[130] G. A. Kraus, Clean 36 (2008) 648-651.

[131] Y. Nakagawa, Y. Shinmi, S. Koso, K. Tomishige, J. Catal. 272 (2010) 191-194.

[132] Y. Shinmi, S. Koso, T. Kubota, Y. Nakagawa, K. Tomishige, Appl Catal B: Environ. 94 (2010) 318-326.

[133] Y. Nakagawa, X. Ning, Y. Amada, K. Tomishige, Appl. Catal. A: Gen. 433-434 (2012) 128-134.

[134] Y. Nakagawa, M. Tamura, K. Tomishige, J. Mater. Chem. A 2 (2014) 6688-6702.

[135] C. Deng, X. Duan, J. Zhou, X. Zhou, W. Yuan, S. L. Scott, Catal. Sci. Technol. 5 (2015) 1540-1547.

[136] T. Kurosaka, H. Maruyama, I. Naribayashi, Y. Sasaki, Catal. Commun. 9 (2008) 1360-1363.

[137] L. Gong, Y. Lu, Y. Ding, R. Lin, J. Li, W. Dong, T. Wang, W. Chen, Appl. Catal. A: Gen. 390 (2010) 119-126.

[138] Y. Zhang, X. Zhao, Y. Wang, L. Zhou, J. Zhang, J. Wang, A. Wang, T. Zhang, J. Mater. Chem. A 1 (2013) 3724-3732.

[139] T. Mizugaki, T. Yamakawa, R. Arundhathi, T. Mitsudome, K. Jitsukawa, K. Kaneda, Chem. Lett. 41 (2012) $1720-1722$

[140] R. Arundhathi, T. Mizugaki, T. Mitsudome, K. Jitsukawa, K. Kaneda, ChemSusChem 6 (2013) 1345-1347.

[141] J. ten Dam, K. Djanashvili, F. Kapteijn, U. Hanefeld, ChemCatChem 5 (2013) 497-505.

[142] S. García-Fernández, I. Gandarias, J. Requies, M.B. Güemez, S. Bennici, A. Auroux, P.L. Arias, J. Catal. 323 (2015) 65-75.

[143] J. Oh, S. Dash, H. Lee, Green Chem. 13 (2011) 2004-2007.

[144] L. Huang, Y. Zhu, H. Zheng, G. Ding, Y. Li, Catal. Lett. 131 (2009) 312-320.

[145] L. Qin, M. Song, C. Chen, Green Chem. 12 (2010) 1466-1472.

[146] S. Zhu, X. Gao, Y. Zhu, J. Cui, H. Zheng, Y. Li, Appl. Catal. B: Environ. 158-159 (2014) 391-399.

[147] S. Zhu, Y. Qiu, Y. Zhu, S. Hao, H. Zheng, Y. Li, Catal. Today 212 (2013) 120-126.

[148] S. Zhu, X. Gao, Y. Zhu, Y. Zhu, X. Xiang, C. Hu, Y. Lia, Appl. Catal. B: Environ. 140-141 (2013) 60-67.

[149] S. Zhu, X. Gao, Y. Zhu, Y. Li, J. Mol. Catal. A: Chem. 398 (2015) 391-398.

[150] S. S. Priya, V. P. Kumar, M. L. Kantam, S. K. Bhargava, K. V. R. Chary, RSC Adv. 4 (2014) 51893-51903.

[151] S. S. Priya, V. P. Kumar, M. L. Kantam, S. K. Bhargava, K. V. R. Chary, Catal. Lett. 144 (2014) 2129-2143.

[152] A. Konaka, T. Tago, T. Yoshikawa, A. Nakamura, T. Masuda, Appl. Catal. B: Environ. 146 (2014) 267-273.

[153] K. Mori, Y. Yamada, S. Sato, Appl. Catal. A: Gen. 366 (2009) 304-308. 
[154] D. Sun, R. Narita, F. Sato, Y. Yamada, S. Sato, Chem. Lett. 43 (2014) 450-452.

[155] E. Arceo, P. Marsden, R.G. Bergman, J.A. Ellman, Chem. Commun. (2009) 3357-3359.

[156] E. Arceo, J.A. Ellman, R.G. Bergman, ChemSusChem 3 (2010) 811-813.

[157] M. Shiramizu, F.D. Toste, Angew. Chem. Int. Ed. 51 (2012) 8082-8086.

[158] J. Yi, S. Liu, M. M. Abu-Omar, ChemSusChem 5 (2012) 1401-1404.

[159] Y. Liu, H. Tüysüz, C. Jia, M. Schwickardi, R. Rinaldi, A. Lu, W. Schmidt, F. Schüth, Chem. Commun. 46 (2010) $1238-1240$.

[160] T. Yoshikawa, T. Tago, A. Nakamura, A. Konaka, M. Mukaida, T. Masuda, Res. Chem. Intermed. 37 (2011) $1247-1256$.

[161] A. Konaka, T. Tago, T. Yoshikawa, H. Shitara, Y. Nakasaka, T. Masuda, Ind. Eng. Chem. Res. 52 (2013) $15509-15515$.

[162] T. Tago, Y. Nakasaka, T. Masuda, J. Jpn. Petrol. Inst. 57 (2014) 197-207.

[163] G. Sánchez, J. Friggieri, C. Keast, M. Drewery, B. Z. Dlugogorski, E. Kennedy, M. Stockenhuber, Appl. Catal. B: Environ. 152-153 (2014) 117-128.

[164] C. Mohr, H. Hofmeister, J. Radnik, P. Claus, J. Am. Chem. Soc. 125 (2003) 1905-1911.

[165] C. E. Volckmar, M. Brona, U. Bentrup, A. Martin, P. Claus, J. Catal. 261 (2009) 1-8.

[166] H. Wei, C. Gomez, J. Liu, N. Guo, T. Wu, R. Lobo-Lapidus, C. L. Marshall, J. T. Miller, R. J. Meyer, J. Catal. 298 (2013) 18-26.

[167] M. Lucas, P. Claus, Chem. Eng. Technol. 28 (2005) 867-870.

[168] Y. Amada, S. Koso, Y. Nakagawa, K. Tomishige, ChemSusChem 3 (2010) 728-736.

[169] M. Tamura, Y. Amada, S. Liu, Z. Yuan,Y. Nakagawa, K. Tomishige, J. Mol. Catal. A: Chem. $388-389$ (2014) $177-187$.

[170] Z. Xiao, C. Li, J. Xiu, X. Wang, C. T. Williams, C. Liang, J. Mol. Catal. A: Chem. 365 (2012) 24-31.

[171] E. van Ryneveld, A. S. Mahomed, P. S. van Heerden, H. B. Friedrich, Catal. Lett. 141 (2011) 958-967.

[172] L. Yu, J. Yuan, Q. Zhang, Y. Liu, H. He, K. Fan, Y. Cao, ChemSusChem 7 (2014) 743-747.

[173] E. van Ryneveld, A. S. Mahomed, P. S. van Heerden, M. J. Green, H. B. Friedrich, Green Chem. 13 (2011) $1819-1827$.

[174] E. van Ryneveld, A. S. Mahomed, P. S. van Heerden, M. J. Green, C. Holzapfel, H. B. Friedrich, Catal. Sci. Technol. 
$4(2014) 832-837$.

[175] S. Zhu, Y. Zhu, S. Hao, H. Zheng, T. Mo, Y. Li, Green Chem. 14 (2012) 2607-2616.

[176] X. Lin, Y. Lv, Y. Xi, Y. Qu, D. L Phillips, C. Liu, Energ. Fuel. 28 (2014) 3345-3351.

[177] D. Sun, Y. Yamada, S. Sato, Appl. Catal. B: Environ. 174 (2015) 13-20.

[178] V. Zacharopoulou, E. S. Vasiliadoua, A. A. Lemonidou, Green Chem. 17 (2015) 903-912. 
Glycerol hydrogenolysis into useful C3 chemicals

\author{
Daolai Sun, ${ }^{\mathrm{a}}$ Yasuhiro Yamada, ${ }^{\mathrm{a}}$ Satoshi Sato, ${ }^{\mathrm{a}, *}$ Wataru Ueda ${ }^{\mathrm{b}}$ \\ ${ }^{a}$ Graduate School of Engineering, Chiba University, Chiba, 263-8522, Japan \\ ${ }^{b}$ Department of Material and Life Chemistry, Faculty of Engineering, Kanagawa \\ University, Kanagawa, 221-8686, Japan.
}

Graphic abstract

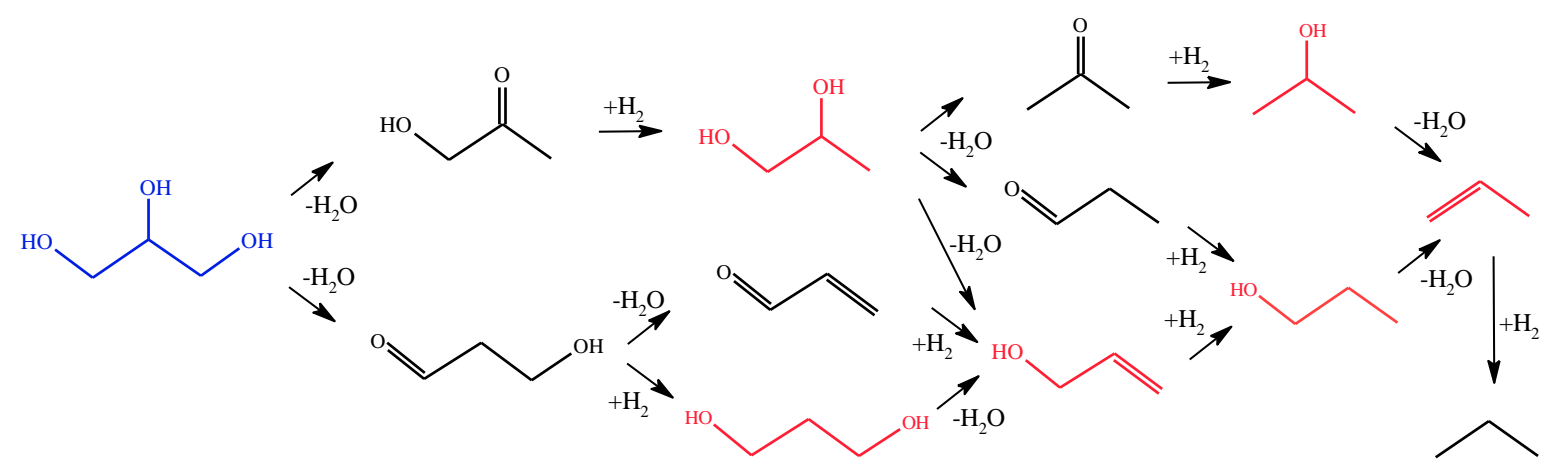

Glycerol hydrogenolysis into useful C3 Chemicals 